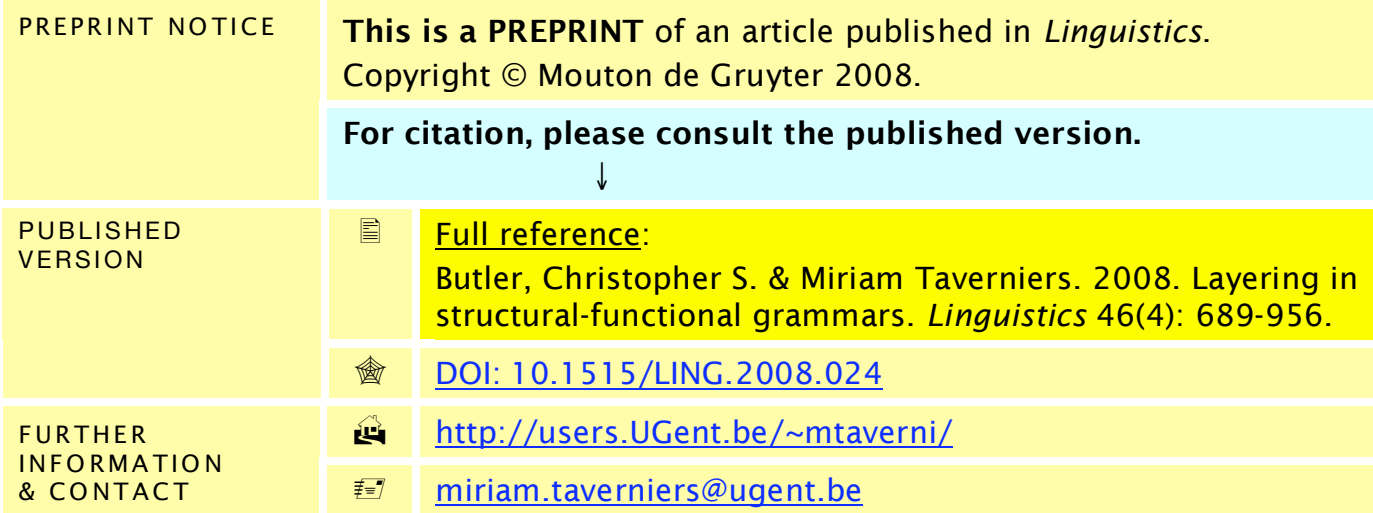

\title{
Layering in structural-functional grammars
}

\author{
Christopher S. Butler and Miriam Taverniers
}

\begin{abstract}
This article presents an overview of the notion of layering in three types of structuralfunctional grammars. Layering is interpreted in a broad sense to refer to two types of linguistic differentiations: (1) on the one hand, a distinction between levels of coding, namely, syntax/grammar, semantics, pragmatics; (2) on the other hand, a differentiation between speaker-related vs. content-related material in language, i.e., a distinction between interpersonal vs. representational or ideational aspects of linguistic structuring. We focus on the way in which layering is theorized in three types of linguistic models where layering plays a crucial role in the design of the theory, namely, Systemic-Functional Grammar (SFG), Functional Discourse Grammar (FDG) and Role and Reference Grammar (RRG). Special attention is paid to recent developments of these theories which have proposed important changes to the conception of layering.

The discussion is organized in terms of four issues: (1) what layers are distinguished (how many?) in the "standard" version of the theory, and how is the relationship between the layers conceived of? (2) What is the motivation and descriptive evidence for the layered model? (3) What is the relationship between the view of a layered linguistic structure and the way in which different levels of encoding are conceived (syntax/semantics/pragmatics)? (4) In what way is the
\end{abstract}


conception of layering related to the way in which the linguistic model views language typology? That is, in a typological perspective, what aspects of layering are regarded as universal, and what aspects differ between languages or typological groups of languages?

\section{Introduction}

The past 40 years have witnessed the steady growth of approaches to grammatical theorising and description which are often brought together under the label 'functional(ist)', and offer a very different perspective on language from the 'formalist' theories typified by those of Chomsky. We shall not add here to the discussion of what constitutes a functional grammar (see Butler 2003a, 2003b, 2005a, 2005b), nor shall we attempt to defend functionalist positions as against formalist ones: recent treatments of this issue from a functionalist perspective can be found in Butler (2003a: Chapter 1), Gonzálvez-García and Butler (2006), and a formalist view on functionalism in Newmeyer (1998, 2000, 2003a, 2003b, 2005); further material on the relationship between functionalism and formalism is available in Darnell et al. (1999) and Butler (in press). It will suffice to say that the central claim of functionalism is that language should be seen first and foremost as a system for communication between human beings, and that the shapes which languages take are strongly conditioned by both the nature of human cognitive capacities and the sociocultural contexts in which, and purposes for which, language is used. Although, as pointed out by Newmeyer (2003a: 687, 2005: 135-136), formalists are not necessarily fundamentally opposed to the concept of functional motivation in itself, they have not regarded such motivations as central to their research program.

In addition to claiming that language is not autonomous from language-external factors but must be explained, at least in part, in terms of such factors, most functionalists would also see syntactic phenomena as being motivated by (and not simply correlating with) meaning, to degrees which vary with the particular theory. Ultimately deriving from these underlying tenets are other criteria to which particular functionalist approaches subscribe to varying extents: the need to tackle everything which is systematic in language, rather than just some kind of 'core' grammar; recognition of the inherent flexibility of language, which Givón (1995: 5) describes in 
terms of the context-dependent, non-atomic nature of meaning, the non-discreteness of linguistic categories, the malleability of structure, the emergence of grammar from the dictates of discourse, and the 'leakiness' of grammatical rules; the use of authentic linguistic productions as an important source of data; an interest in linguistic typology; and an approach to language acquisition which focuses on the child's construction of his or her own grammar, using the input s/he is exposed to, together with general cognitive constraints and dispositions for learning.

Within the broad range of functional approaches, we may distinguish a smaller group of STRUCTURAL-FUNCTIONAL APPROACHES, which are committed to the study of both meaning and formal structure, and of the relationships between the two (see Van Valin 1993: 2). A subset of such approaches are what Butler (2003a: 62) labels STRUCTURAL-FUNCTIONAL GRAMMARS, which are generative, in that "they provide (at least potentially) an explicit framework of rules and principles, linked in specified ways, by means of which the structure and interpretation of linguistic expressions can, in principle, be exhaustively described" (Butler 2003a: 61). According to this criterion, what has been called 'West Coast Functional Grammar', typified by the work of scholars such as Talmy Givón, would count as a structural-functional approach, but not as a structural-functional grammar, since it does not attempt to provide an integrated framework for description of the kind just defined. Butler (2003a: Chapter 2) argues that there are three central exemplars of structuralfunctional grammars: the Functional Grammar (henceforth FG) pioneered by Dik (see particularly Dik 1997a, 1997b), the Role and Reference Grammar (RRG) of Van Valin (Van Valin 2005, Van Valin and LaPolla 1997), and the Systemic Functional Grammar (SFG) of Halliday (Halliday and Matthiessen 1999, 2004). The aim of the present introduction is to give an overview of the state of the art in these three structural-functional theories, as a background against which the papers collected together in this special issue of Linguistics may be interpreted.

A particularly striking feature of structural-functional grammars is the layering which is explored in the papers which follow in this special issue. Basically, the claim is that the clause, and to some extent also phrasal units, can fruitfully be analysed in terms of a number of layers which are related to the functions which language serves in communication, and go beyond the usual treatment in terms of levels of syntax, 
semantics and pragmatics, though they are, as we shall see, related to these traditional levels in interesting ways. We would certainly not wish to claim that the layering principle is exclusive to structural-functional grammars: indeed, certain aspects of layering are also evident even in formalist models, as well as in other functional approaches. It is nevertheless fair to say that this principle is of crucial importance to the set of models we are considering here.

This paper will be organised as follows. First, in $\S 2$, we shall outline briefly the history of layering in functional grammars, without any detail of particular theories. Then, in $\S \S 3-5$, we discuss the implementation of the layering principle in SFG, RRG and Functional Discourse Grammar (FDG), this last being most recent manifestation of Dik's FG. The discussion of each theory will be organised in terms of four key issues:

(i) What is the overall nature of the theory? In particular, what layers are proposed in the 'standard' model, what is their nature and how are they related?

(ii) What is the evidence for the layering?

(iii) What relation do layers have with the traditional levels of syntax/semantics/ pragmatics?

(iv) What aspects of layering are considered to be universal, and which vary according to the particular language or typological group? More generally, how does the view of layering taken in the theory relate to its view of language typology?

Much of the material presented in these sections is also discussed in Butler (2003a, 2003 b). A brief comparative summary is given in $\S 6$. 


\section{A brief history of layering in structural-functional grammars}

Halliday (1968: 207) notes that there are many references in the literature to the multiple functions of language. Important antecedents of layering in structuralfunctional grammars can be found, for example, in the work of Bühler (1934), who classified such functions into 'Darstellung' (REPRESENTATION), 'Ausdruck' (EXPRESSION) and 'Appel' (VOCATIVE) types. This classification was further developed by Prague School linguists (see Vachek 1966). Jakobson, in particular, modified and extended Bühler's scheme into a model of the whole communicative process, replacing Vocative by an instrumentally-oriented CONATIVE function, renaming the representational function as REFERENTIAL and the expressive as EMOTIVE, and adding three further communicative functions, the CODE which is used, the CHANNEL of communication and the POETIC (artistic, creative) function of language. A summary of these and other proposals can be found in Lyons (1977: 51$55)$.

The important point to note about the functional categories of Bühler and Jakobson is that they are external to language itself, though conditioning the particular forms which communication may take. The layering principle was born when Halliday showed, initially in the late 1960s, that external function is reflected in the internal structuring of the language. As we shall see in $\S 3$, Halliday proposes that in all languages, both the paradigmatic selections which can be made from the grammar ${ }^{1}$ and the syntagmatic structures which are formed by the realisation of sets of paradigmatic choices are patterned in relation to the basic functions which language is called upon to serve: the representation of the world outside us and in our own heads, the setting up and maintenance of interpersonal relations, and the formation of text which is cohesive and also coherent with respect to the situation. These considerations apply not only to the clause, but also, to varying extents, to phrasal units.

The other main influence on layering in current functional grammars was Foley and Van Valin's (1984) early account of RRG. A central tenet of this theory, which cannot

\footnotetext{
${ }^{1}$ More accurately, the 'lexicogrammar' - see later discussion.
} 
be too highly emphasised, is its strongly typological orientation: from the very beginning, proponents of RRG have sought to discover linguistic universals and to develop a theory which is adequate for any type of language. This requirement strongly influenced the layered model of clause structure which was proposed. Three concentric layers of organisation were posited: the periphery, within which was the core, within which was the nucleus. This type of layering scheme has persisted, in a modified form, into present-day RRG and will be described in detail in $\S 4$. Layering applies to both the clause and the noun phrase.

In the late 1980s, layering also found its way into FG, which again has a clearly typological orientation. In his first major exposition of FG, Dik (1978) had distinguished between PREDICATES and the TERMS which act as arguments and (optional) satellites for these predicates, the combination of predicate and arguments constituting the NUCLEAR PREDICATION, which when embellished with satellites becomes an EXTENDED PREDICATION. Hengeveld (1986, 1987, 1988) develops this scheme into one with four layers (predicate, predication, proposition, illocution), each with its own set of operators. Hengeveld (1989) then characterises this scheme in terms of a distinction, already implicit in the 1988 account, between two functions of the predication: to describe the external situation referred to in the speech act, and to represent the propositional content of that speech act. This gives rise to a model in which the predicate and predication layers are seen as constituting a REPRESENTATIONAL LEVEL and the proposition and illocutionary layers as forming an INTERPERSONAL LEVEL. Hengeveld (1989: 128, 1990a: 3) recognises his indebtedness to both Halliday and Foley and Van Valin with respect to the concept of layering now incorporated into the FG model. The basic architecture of four layers was taken on board in Dik's The Theory of Functional Grammar (Dik 1989), though the higherorder grouping into representational and interpersonal levels is curiously absent from this account, and in the second edition of the book we find only a brief reference to the fact that the "descriptive or representational part of the clause structure" ends with the completion of the extended predication (Dik 1997a: 52), with no complementary reference to the upper levels as constituting an interpersonal level.

We shall see that in the latest model of FG, Functional Discourse Grammar (Hengeveld 2004a, 2004b; Mackenzie and Gómez-González 2005; de Groot and 
Hengeveld 2005; Hengeveld and Mackenzie 2006, in preparation) the representational and interpersonal are two of the four levels within the grammatical component of the model, the others being the morphosyntactic and the phonological.

Layering has also been shown to apply to the noun phrase, and there are strong parallels between the clause and NP in this respect (Rijkhoff 1992, 2002, this volume).

\section{Layering in systemic functional grammar}

\subsection{An Overview}

In this overview of SFG, we shall deal only with what is sometimes called the Sydney grammar, developed by Halliday and his colleagues. Unfortunately, lack of space precludes a comparison of this version with that known as the Cardiff grammar which has been elaborated by Fawcett and his colleagues. The two versions share many fundamental views and assumptions, but also show important differences (see especially Fawcett 2000).

As we stated in §0, Halliday’s early (late 1960s) description of linguistic structure in terms of different types of functional categories marks the birth of a notion of linguistic 'layering' (although the term 'layering' was not used by Halliday). It is indeed Halliday's conception of the internal structure of language as being organised in terms of three metafunctions - ideational, interpersonal and textual - that lies at the basis of what later became SFG, and that has influenced to an important extent the 'layered' model of language later proposed in RRG and FG (see $§ \S 4-5$ below). ${ }^{2}$

Halliday developed his concept of metafunctional diversity in language alongside a conception of different levels in linguistic structuring (especially semantics and lexicogrammar) in terms of a Hjelmslevian stratification. The notions of stratification and metafunctional diversity indicate two different types of layering that are inherent in SFG, and together form the basis of the functional motif underlying SFG. The

\footnotetext{
${ }^{2}$ For more detailed discussions of SFG which pay attention to the theoretical motifs of metafunctional diversity and stratification, see Butler (1985, 1989), Fawcett (2000), Taverniers (2002).
} 
nature of these two types of layering in SFG can only fully be grasped if they are considered in the larger framework of the design of the theory as a whole, especially in relation to another theoretical motif which provides the first part of the theory's label, viz. the systemic motif. ${ }^{3}$

SFG is built up around the fundamental tenet that language is a meaning potential: language is seen as a potential from which choices can be made in particular environment. The notion of a system of choices is formalised in the most important descriptive tool within SFG, viz. the system network. Each system in a system network is a point of choice, consisting of an entry condition (the environment of the choice), a system name, and a number of systemic terms or features (the choices available in the environment). Thus each system represents a particular dimension along differentiations which are made in order to characterise a linguistic phenomenon (an aspect of structure).

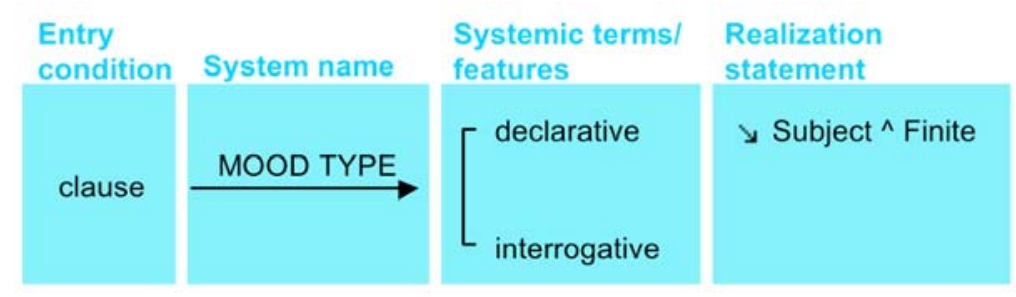

Figure 1: Elements of a system in SFG

An example is given in Figure 1. The difference between [declarative] and [interrogative] indicates a dimension of choice (in this case, a contrast), labelled MOOD TYPE (the name of the system), which is available at clause level. In SFG, each linguistic categoryis defined in terms of a selection of a feature (or a combination of selections of features) from a system network (or from different system networks). Besides this definition, each category is also characterised by means of a realisation

\footnotetext{
${ }^{3}$ Halliday (1985, 1994 - and the third edition, Halliday \& Matthiessen 2004) and Matthiessen (1993) are the major publications that represent the 'standard' development of the SFG model of the multifunctional lexicogrammar. Halliday's major publication An Introduction to Functional Grammar (1985) is an overview of the functional dimension of the theory, specifying the functional structures for English in terms of the three metafunctions. Matthiessen's Lexicogrammatical Cartography (1993) focusses on the systemic dimension of the theory, by offering fine-grained system networks for all metafunctional components, accumulating more than a decade of work on the grammar of English.
} 
statement. Such realisation statements, an example of which is also incorporated in the system network (cf. Figure 1), specify structural (syntagmatic) characteristics by which the selected systemic feature(s) is/are realised or encoded in the lexicogrammar (or in phonology). The symbol preceding the realisation statement, "\" means "is realised by'. In the example at hand, the feature [declarative] is realised as a structure in which the Subject precedes (the sign "^” indicates a sequence) the Finite element. With its twofold set-up containing systems of features as well as realisation statements, the system network and its associated realisation statements are regarded as a tool which represents both paradigmatic and syntagmatic organisation (respectively) axes in the SFG model of language.These two dimensions of the system network are usually referred to in SFG as the system-structure complementarity.

We can now turn to the functional dimension in SFG, and its two types of layering. In SFG, language is viewed as comprising a number of levels of symbolisation, which are called strata - a label that is inspired by Hjelmslev's notion of 'stratification' in language. The major strata are: context, semantics, lexicogrammar and phonology/graphology. Following Martin and Matthiessen (1991), they are commonly represented in SFG by means of cotangent circles (see Figure 2). The explicit stratified conception of language creates the possibility of identifying and examining linguistic phenomena from alternative views. In this sense, the notion of stratification offers what Halliday (1996: 16) calls a trinocular vision: any linguistic system can be looked at from its own level, from around; from the higher stratum, from above; and from the lower stratum, from below. Being a functional theory, SFG assigns priority to the perspective 'from above': in order to give a functional explanation of a phenomenon one must approach it 'from above', from a semantic perspective.

Apart from being stratified, language as a semiotic resource is seen as being organised in terms of three metafunctions: ideational, interpersonal, and textual. Following Matthiessen (1993), the metafunctions can be represented as three general areas spread across the different strata of language, as in Figure 2. 

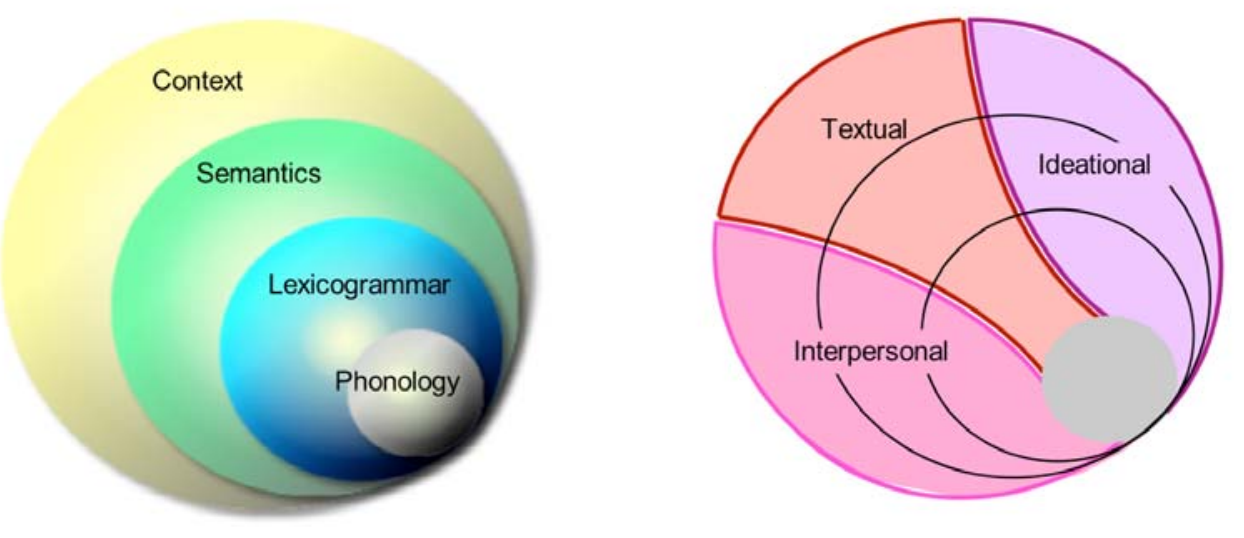

Figure 2: Two types of layering in SFG: stratification and metafunctional diversity

The interpersonal metafunction "serves to establish and maintain social relations: for the expression of social roles, which include the communication roles created by language itself - for example the roles of questioner and respondent, which we take on by asking or answering a question; and also for gettting things done, by means of the interaction between one person and another" (Halliday 1970: 143).

The ideational metafunction "serves for the expression of 'content': that is, of the speaker's experience of the real world, including the inner world of his own consciousness" (Halliday 1970: 143). The ideational metafunction is seen as comprising two sub-components: an experiential sub-function and a logical subfunction. The experiential sub-component is concerned with the construal of experience as such by means of processes, participants, circumstances, and the like; whereas the logical sub-component serves to establish links between various stretches of construals of experience, by means of relations such as coordination, subordination, and so on.

The textual metafunction "enables the speaker or writer to construct 'texts', or connected passages of discourse that is situationally relevant; and enables the listener or reader to distinguish a text from a random set of sentences" (Halliday 1970: 143). The textual metafunction is regarded as being of a second-order nature compared to the other two metafunctions. On the one hand, it is carried by the ideational and interpersonal metafunctions, since it is ideational and interpersonal resources together that make it possible to create a larger stretch of discourse. On the other hand, the textual metafunction has an 'instrumental' or 'enabling' relation (Halliday 1970: 325) 
to the other two components: it enables the integration of ideational and interpersonal meanings by providing them with a texture, i.e. by presenting them as texts.

The idea of 'metafunctional diversity' is a hypothesis about language which is relevant at two levels: [1] on a general level, it is a hypothesis about the way in which language is capable of functioning in the whole of human life, and [2] on a more particular level, it is a hypothesis about the way in which language, and most notably linguistic structure (lexicogrammatical form), is organised. In general, it is referred to in SFG as the metafunctional hypothesis.

Because the metafunctions are interpreted as pertaining to the general functioning of language (cf. [1] in the previous paragraph), they are seen as permeating the whole linguistic system. This is why, in its most general theoretical conception in SFG, metafunctional diversity is seen as a dimension that cross-cuts the stratification of language into different levels of symbolisation; and it is this ideal representation that is visualised in Figure 2 above. In this sense also, the relationships between the different 'content' strata - more specifically, between the levels of lexicogrammar and semantics on the one hand, and between semantics and context on the other, are regarded as solidary or 'natural', in that they are functionally motivated. ${ }^{4}$

The way in which the metafunctional hypothesis shapes the view of linguistic structure in SFG (cf. [2] above) can only be understood in relation to the most important representational and theoretical tool in SFG, viz. the system network. It is in this context, and especially in relation to the system-structure complementarity, that the metafunctional layering inherent in SFG becomes clear.

When Halliday first presents the idea of different functional areas in the organisation of language, it is motivated in terms of a clustering of different types of systems four groups, indicating four distinct functional components (Halliday 1967a, 1967b, 1968). As Halliday sees it, the metafunctions represent three large areas of choice in language. ${ }^{5}$ Hence, the overall paradigmatic organisation of language is subdivided

\footnotetext{
${ }^{4}$ See Cléirigh (1998) for an application of the metafunctional hypothesis to the phonological stratum.

${ }^{5}$ In "Notes on transitivity and theme", Halliday distinguishes three "main areas of syntactic choice" (viz. transitivity, mood and theme) (Halliday 1967b: 199) and later "four components in the grammar of English representing four functions that the language as a communication system is fulfilling" (viz. experiential, logical, discoursal and speech functional or interpersonal) (Halliday 1968: 207-209). In
} 
into four different system networks: experiential, logical, interpersonal and textual, each of which has its own dependent and interlocking sub-systems. Importantly, the experiential, logical, interpersonal and textual networks are not seen as separate options in a larger network, rather, they are simultaneous sets of systems. Taking the clause as a point of origin, examples of simultaneous system networks from the interpersonal, ideational and textual metafunctions are those of MOOD, TRANSITIVITY and THEME. Overviews of various types of systems are often represented by means of a class-function matrix, the rows indicating different points of origin, and the columns specifying the different kinds of systems that are available within each metafunctional component. An example of a class-function matrix is presented in Table $1 .^{6}$

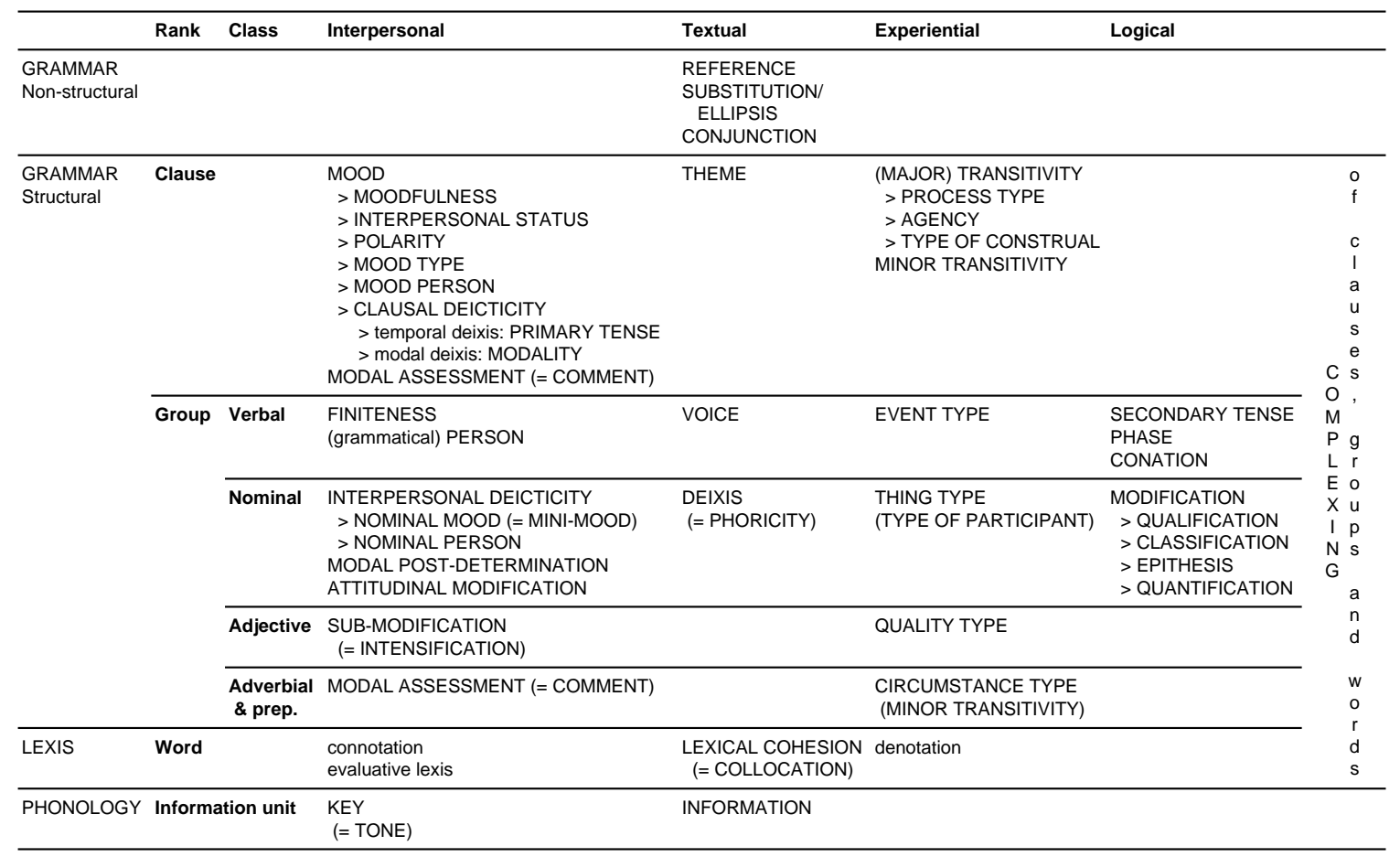

Table 1: Class-function matrix of English systems in SFG

With regard to structure, the metafunctions are indicated in SFG as simultaneous strands of structuring: each metafunction, and thus each path through a metafunctional

"Functional diversity in language", these types of systems are interpreted in terms of three "functions of language" (Halliday 1970: 324ff., our emphasis), which are called ideational/experiential, interpersonal and textual (compare also Halliday 1976a: 29, 1973a/1971: 66).

${ }^{6}$ The first class-function matrix was proposed in Halliday (1970: 327) and forms the basis for various subsequent refinements. The diagram given here is based on the system networks proposed in Martin (1992), Matthiessen (1993) and Halliday and Matthiessen (1999). 
network of options, contributes a strand or layering of structuring. This is represented as three (or four, if taking into account the separate logical sub-component) layers of functional configurations mapped onto one syntagm (represented by a sequence of grammatical classes), as shown in Figure 3. It is important to note that the metafunctional layers are simultaneously present as parallel strands of structuring: each element in the syntagm can be linked to an ideational, an interpersonal and a textual function. For example, in the interpersonal layer, there are the elements of the Mood Adjuncts and the Finite (comprising modal finiteness), but also the Subject and the remainder of the clause (called the Residue) are interpersonal categories. In this respect, SFG differs from both $R R G$ and $F(D) G$, which propose a hierarchical layering of structure (cf. $\S \S 4-5$ below).

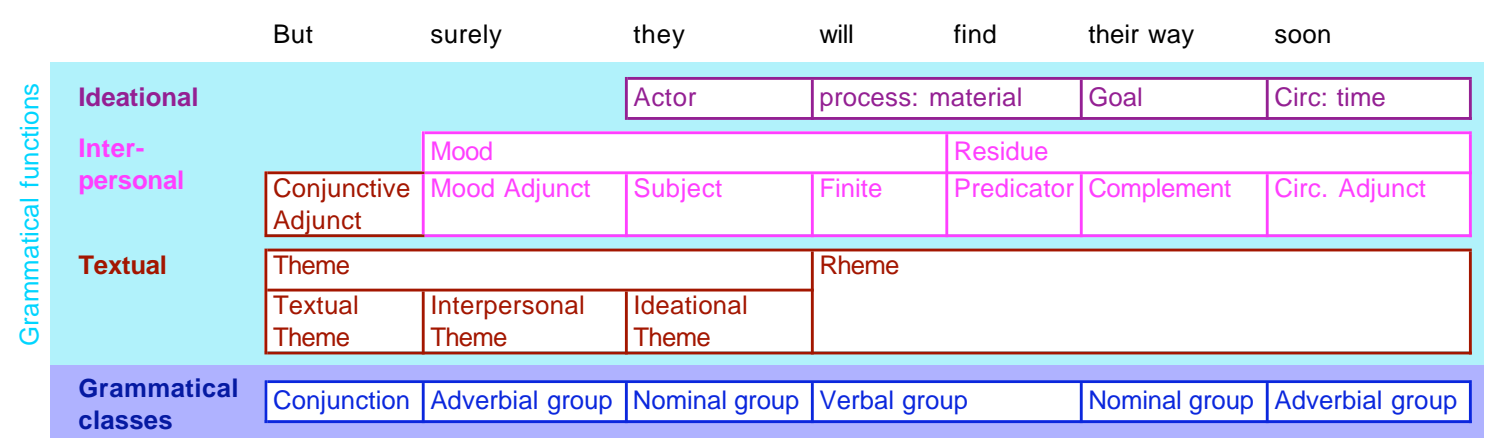

Figure 3: Structural analysis in SFG by means of simultaneous metafunctional strands

\subsection{Evidence for layering ${ }^{7}$}

The conception of a stratified model of language in SFG was inspired by two frameworks of studies: the study of language development and an investigation of the use of language in social contexts.

The stratification of 'semantics' and 'lexicogrammar' that was proposed by Halliday in the 1970s (cf. Halliday 1973a/1971, 1976a, 1973b, 1977, 1978a), was based on an

\footnotetext{
${ }^{7}$ Naturally, the type of evidence for layering in SFG is inherently intertwined with the kind of phenomena focussed on in different stages of SFG. However, as has been noted at various places (e.g. Butler 1989: 8, 2003a), the changes in the theory have not always been made very clear. This remark also applies to the following section on the relation between layering and the levels of syntax, semantics and pragmatics.
} 
exploration of language development, more specifically the question of how the early linguistic system (proto-grammar) of a very young child is gradually elaborated into an adult language. According to Halliday (1976b/1973, 1984), the proto-linguistic system can be modelled in terms of a simple coding relationship between a content plane and an expression plane, in the Hjelmslevian sense. As the child's language system develops, it has to fulfill more functions in more diversified contexts, and a one-to-one relationship between content and expression no longer obtains. In modelling this expanding resource, Halliday claims, a new interface is needed, in addition to the levels of content and expression. This is the interface between 'semantics' ('meanings') and 'lexicogrammar' ('wordings') within the content plane. The need for both a lexicogrammar and a semantics in the adult language system is explained by Halliday in terms of an internal stratification of the content plane, as visualised in Figure 4: the content plane rather than the expression plane is internally stratified, since the relationship between 'lexicogrammar' and 'semantics' is 'natural' (i.e. it is functionally motivated), whereas phonology generally relates to 'lexicogrammar' in an arbitrary way.

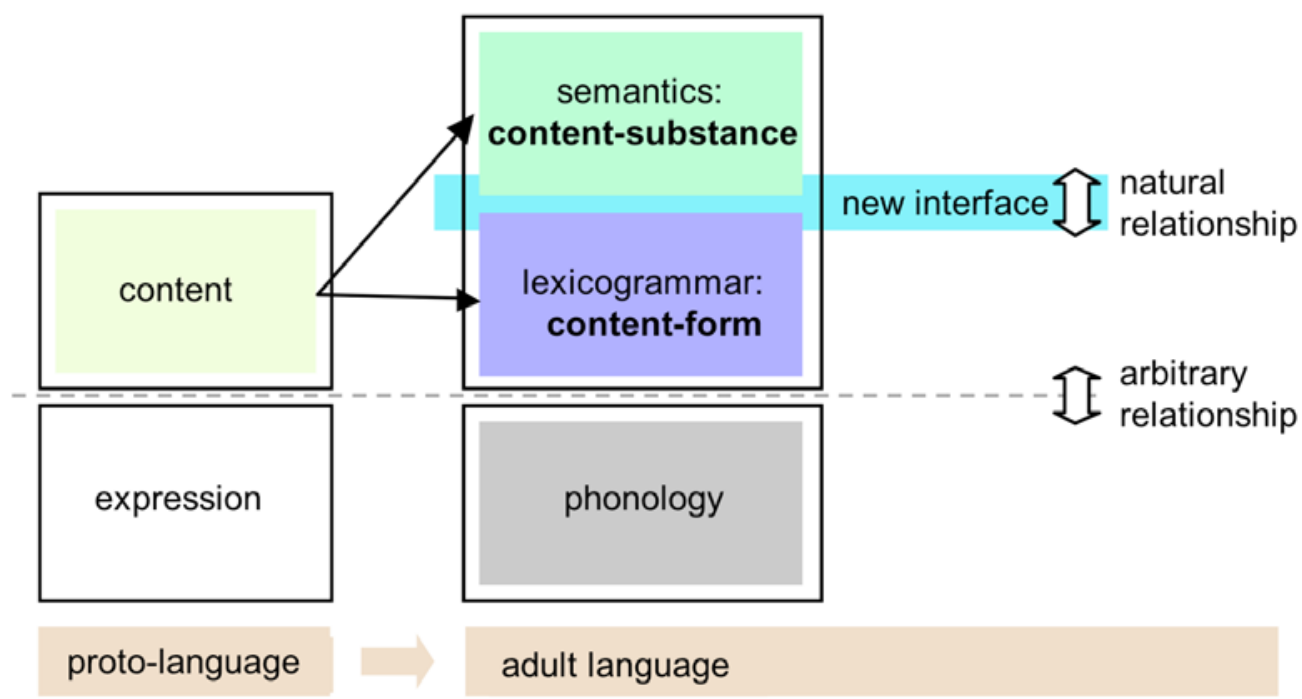

Figure 4: Stratified layering in SFG: stratification of the content plane into a semantics and a lexicogrammar in the adult language system

The study of language development inspired a stratified conception of language 'from around': starting from the initial content-expression relationship in proto-grammar, in a model of adult grammar an additional interface within the content plane becomes necessary in order to account for more complex types of utterances. 
The investigation of the use of language in social contexts (so-called studies of language in relation to 'social man' (Halliday 1973a/1971: 48, 1978b)) in the 1970s calls for a stratification of language which is motivated 'from above'. In this framework, language in general is regarded as one type of social behaviour. In theorising the way in which language is able to function in social settings, a 'semantic' stratum is needed as a 'bridge' in between a stratum of (social) context and a lexicogrammatical stratum. More specifically, in keeping with the fundamental view of language as a resource, and the important underlying notion of 'choice' (cf. §3.1), social behaviour is conceptualised as "behaviour potential": "[i]t is what the speaker can do" (Halliday 1973a/1971: 51; our emphasis). In order to link language to the more general social behaviour in which it is embedded, the relationship between 'what the speaker can do, socially' and 'what the speaker can say, in language' must be defined. This relationship, Halliday argues, is not a direct one, since 'can do' as such is not a linguistic concept: it is mediated through the additional stage of 'what the speaker can mean'. Hence, an important role is assigned to 'semantics' as an intermediate level between context and lexicogrammar: the 'semantic' stratum indicates those aspects of social context that are intrinsically meaningful, i.e. those aspects that are coded in the lexicogrammatical system of a language. Because of its role as an interface between social context and lexicogrammar, the semantic stratum is also called a sociological semantics or socio-semantics (cf. Halliday 1973c/1972).

The initial modelling of language as metafunctionally diversified in SFG was inspired by three general frameworks of systemic functional studies in the 1960s and 1970s: grammatical studies, and the two frameworks mentioned above in relation to the stratified view of language, viz. investigations into language development and explorations of the use of language in social contexts.

As we have seen in $\$ 3.1$, in his early work on grammar Halliday distinguished three or four areas of syntactic choice - three or four clusterings of systems, which he linked to areas of 'meaning' and which he called functions of language, and later 'metafunctions'. The four components of the linguistic system are described as being related to the way in which language is able to function in general:

If we represent the set of options available to the speaker in the grammar of the English clause, these options group themselves into a small number of 
subsets, distinct from one another in that, while within each group of options there is a very high degree of interdependence, between any two groups the amount of interdependence, though by no means negligible, is very much less. This provides a syntactic basis for the concept of language functions [...] It seems possible to set up four components in the grammar of English representing four functions that the language as a communication system is required to carry out [...] (Halliday 1968: 207-208)

In the stratified system of language, these components of the lexicogrammar are seen as the manifestation of "functionally defined areas of meaning" (Halliday 1976a: 29). Grammatical structure is seen as "the means whereby the various components of meaning, deriving from the different functions of language, are integrated together" (ibid.). The clustering of different types of systems into functional groups was the first basis for the development of the metafunctional hypothesis in SFG. As we shall see below, Davidse's work on the notions of agnation and enation as two complementary types of systemic relationships provides a further systemic basis for the metafunctional layering in SFG.

Just as it formed an inspiring background for setting up a stratified model of language, Halliday's investigation of language development, undertaken in the 1970s, formed further support for the idea of metafunctional diversification which had first appeared in his studies of grammar. In a proto-grammar, where a one-to-one relationship obtains between content and expression, simple linguistic signs serve to function in a limited range of contexts, so that a small set of uses of language can be distinguished. Halliday (1973c/1972) distinguishes seven types of such functions, and calls them macro-functions: instrumental, regulatory, interactional, personal, heuristic, imaginative and representational. As the proto-grammar expands, language is used in more and more diversified social contexts, and as a result, the linguistic signs become more complex: a single utterance can now combine various of the earlier 'simple' uses of language. This process, according to Halliday, engenders and is in turn enabled by an internal stratification of the content plane, as we have seen above. The new interface within the content plane (semantics/lexicogrammar) is crucial in the development of an adult language system, where the functioning of complex many-to- 
many relations between expressions and forms in varied social contexts is organised through an intermediary 'semantic' stratum.

In adult language, the semantic stratum is seen as being shaped into three distinct metafunctional components of meaning: ideational, interpersonal and textual (Halliday 1970: 325). These components are called 'metafunctional' because they are general, abstract groupings compared to the more specific macro-functions of protogrammar. In their role of modelling the functional complexity of adult language (i.e. the many-to-many mappings between contents and expressions functioning in a multitude of contextual settings), the metafunctions are regarded as being simultaneously present in each act of creating meaning.

In the framework of the study of language in different social contexts (cf. especially Halliday's (1978b) Language as Social Semiotic), it became clear that the hypothesis of the metafunctional organisation of language could be related to a distinction between three dimensions of contextual variation that had already been made in earlier work: field, tenor and mode (e.g. Halliday, McIntosh and Strevens 1964, Strevens 1964, Spencer and Gregory 1964, Gregory 1967). Hence, in Language as Social Semiotic and later work, Halliday correlates the distinction between ideational, interpersonal and textual with the contextual dimensions of field, tenor and mode. This forms the basis for viewing the stratum of context itself as being metafunctionally diversified into three components (Halliday 1978a, and especially 1977). Field (ideational) concerns the type of social action whith takes place in a text, determining the experiences that are construed, especially the 'subject-matter'. Tenor (interpersonal) refers to the social role relationships that are enacted in language, determining the types of speech function roles which are taken up by the interlocutors. Mode (textual) is the type of symbolic organisation (the status of the text as instrumental to field and tenor), including the medium (e.g. written vs. spoken language).

In later studies of SFG, it is especially the systemic dimension and the structural dimension of the metafunctional hypothesis that receive most attention. The systemic evidence for a metafunctional layering in SFG is further fleshed out in the work by Davidse. By reconsidering the relationship between features in systemic functional networks in relation to Gleason's concept of agnation, Davidse (1998) reveals an 
important difference between the inherent organisation of interpersonal and experiential networks: interpersonal systems are based on agnation, whereas experiential systems are based on enation.

Gleason introduced the concepts of agnation and enation in his 1963 textbook, Linguistics and English Grammar, which belongs to a generation of 'generalstructuralist' textbooks (assembling the insights which had been achieved in the major schools of structuralism), which appeared in North-America and Europe in the period 1955-1965, on the verge of the emergenece of more specific (post-)structuralist linguistic schools, especially in Europe, and just before the rise of Chomskyan transformational-generative grammar in the US. In Gleason's book, the terms enation and agnation are proposed to refer to two "contrasting types of relations [between structures], neither of which can exist without the other" (Gleason 1963: 199). Two sentences are regarded as enate if they are structurally identical, or, in Gleason's terms, "if the elements (say, words) at equivalent places in the sentences are of the same classes" (Gleason 1963: 199). Gleason defines agnation as a relationship between constructions which have "the same vocabulary items" but "different structures". Examples of enate and agnate relationships are shown in (1) and (2), respectively:

a. The dog bit the man.

b. The cat ate the canary.

(2) a. The dog bit the man.

b. The man was bitten by the dog.

If larger groups of constructions are considered rather than pairs of expressions in isolation, Gleason claims, it appears that enation and agnation are interdependent. As shown in Table 2, a systematic relationship of agnation (shown by a double arrow) holds between groups of constructions within which all members are syntagmatically identical, i.e. groups of enate constructions. Thus, a variation between two agnate types of construals, such as active versus passive, as in Table 2, applies to a group of expressions which are enate. Conversely, a relationship of enation between different expressions can be recognised on the basis of agnation; and this observation provides a more exact definition of enation: two expressions are enate if they share the same sets of agnates. The fact that the expressions in (3)a, (4)a and (5)a on the one hand, and (6)a on the other hand, enter into different relationships of agnation indicates that 
they are not to be regarded as enate (Gleason 1963: 203), and hence, that they have to be classified into two groups.
a. A stranger was seen by $\Leftrightarrow$
b. The man saw a stranger.
c. *The man saw to be a stranger.
(4) a. The man was bitten by $\Leftrightarrow$ b. The dog bit the man. the dog.
c. *The dog bit to be a man.
a. The glass was broken $\Leftrightarrow$ by the cat.
b. The cat broke the glass.
c. *The cat broke to be the glass.
(6) a. *A stranger was seemed by the man.
b. The man seemed $\Leftrightarrow$ a stranger.
c. The man seemed to be a stranger.

Table 2: Patterns of agnation $(\Leftrightarrow)$ in a set of sample clauses

Davidse (1998) projects Gleason's insights about the relationsips of agnation and enation onto the systemic relationships between features in the system networks found in SFG. She finds that the primary differentiations in experiential networks are based on enation: the features in an experiential network indicate distinct verb classes, which are defined on the basis of sharing particular verbal alternations. For example, the class of [effective] verbs allows the alternation active/passive voice, an alternation which is not available for the class of [middle] verbs. Conversely, in interpersonal and textual systems, the options are agnates: they are general types of possible construals, which can apply either to any kind of clausal syntagm (for example, the features [unmarked theme] or [polar interrogative] in the textual and interpersonal systems), or they can apply to relatively large structures which can be specified in terms of experiential features (for example, the textual feature of [passive] is only available for the experiential class of [effective] constructions). Importantly, this means that experiential categories are lexically-based verb classes that can be differentiated on the basis of interpersonal and textual agnation tests, while interpersonal and textual categories are based on their applicability to different types of (experientially distinguished) verb classes.

The structural dimension of the differentiation between metafunctions was first clear in Halliday's work in relation to the distinction between logical and experiential components as two sub-functions within the ideational metafunction. In his paper "Modes of meaning and modes of expression", Halliday (1979) assigns a particular type of structure to each of the three metafunctions, so that three metafunctional realisation patterns ("modes of expression") are distinguished, as correlating with 
three metafunctional "modes of meaning". Halliday argues that linguistic structure can be patterned in three complementary ways: configurational, prosodic and culminative-periodic structuring. Ideational structure is seen as configurational: it is a constellation of distinct elements. Within the ideational metafunction, the experiential and logical types of structuring, viz. constituency-based and dependency-based structurings, are seen as two complementary types of configurational patterning. The interpersonal mode of expression is defined as prosodic: interpersonal meanings, such as realised by modal verbs or modal adjuncts, is described as being "strung throughout the clause as a continuous motif or colouring": it is "distributed like a prosody throughout the continuous stretch of discourse" (Halliday 1979: 66). Textual meaning is regarded as being realised in a culminative-periodic structure, in which two systems of prominence (thematic prominence and focal prominence, dealt with in the textual systems of THEME and INFORMATION respectively) organise the textual stretch of discourse into a number of message units or "quanta of information" succeeding one another.

Halliday relates the general metafunctional modes of expression to Pike's view of language as particle, field and wave, which was based on the different appearances of light (as particle, field, and wave), as studied in physics: according to Halliday, the ideational mode of realisation is particulate, the interpersonal field-like, and the textual wave-like. Pike (1972/1959) interpreted his threefold conception of language in terms of three complementary perspectives, each of which brings out a particular facet of the nature of language. Although Halliday's metafunctional components are different from Pike's definitions of language as particle, field and wave, the link which Halliday makes with Pike's theory emphasises the complementarity of the three metafunctions at the level of lexicogrammatical structure (see also Halliday 1977: 197).

\subsection{The relationship between layering and the levels of syntax, semantics and pragmatics}

As we have seen in $\$ 3.1$, the differentiation between ideational, interpersonal and textual metafunctions on the one hand, and that between context, semantics and lexicogrammar on the other hand, refer to two distinct types of layering in SFG. In the 
most abstract, theoretical and ideal view, the two dimensions are interpreted as crosscutting one another (see especially Figure 2 above).

In the 'standard' model, the development of the multifunctional description of language has taken the form of a gradual refinement of the system networks and the functional structures for each metafunction. The evolution from Halliday's early work to the recent networks is characterised by two tendencies. ${ }^{8}$ First, as we have seen above, the model became gradually more 'semantic': this can be seen in the features of the networks themselves and is rooted in Halliday's belief that a functional grammar should be pushed as far as possible to the semantics. Second, and concomitant with this, because of the important role assigned to paradigmatic thinking (cf. the 'systemic' dimension of SFG), much less attention has been paid to purely syntagmatic features of language. The commitment to paradigmatic thinking and to a 'semantic' description lies at the basis of Halliday's systematic avoidance of the term 'syntax', and also of the term 'pragmatics'.

In the introductory chapter of An Introduction to Functional Grammar, Halliday (1994: xiv) distances himself from the traditional threefold distinction syntax/semantics/pragmatics, because, as he sees it, this distinction suggests an opposition between syntax and semantics - a view, he adds, that lies at the basis of a formal linguistics, especially a linguistics rooted in the philosophy of language. A second reason Halliday adduces for rejecting the syntax/semantics/pragmatics distinction is that this distinction reflects the history of western linguistics, in which first morphology was studied, and this formed the stepping-stone to studies in syntax, and so on. It is this direction of reasoning, in which one starts from forms and then asks questions about what these forms might mean, which Halliday strongly denounces, since, in his view, a functional grammar should start from meaning and then ask "how are these meanings expressed" (Halliday 1994: xiv).

In a 1987 interview (see Thibault 1987), on being asked why he does not make the distinction between semantics and pragmatics, Halliday answers:

\footnotetext{
${ }^{8}$ For a more detailed account of the relationship between lexicogrammar and semantics in the history of SFG, see Butler (1996: 165ff, 2003a: esp. 211ff), Taverniers (2002: Ch.4).
} 
I've never seen that it's necessary. [...] it seems to me that pragmatics is simply the name of the semantics of the text. I'm not just making a terminological point. It seems to me that a theory of semantics must encompass both the system and the process in exactly the same way that the grammar encompasses both the system and the process. We don't want a separate thing called pragmatics. (Halliday in Thibault 1987: 611)

While the rejection of a separate level of 'pragmatics' by Halliday is very much in keeping with his view on the syntax/semantics/pragmatics distinction and the prioritising of a 'semantic theory', as we have just seen, there is another aspect to it that has to do with the relationship between type and token, and, more fundamentally, with the systemic dimension of SFG. Halliday interprets pragmatics, as a theory of language in use, in terms of an actualisation of language in particular texts. In SFG, this concept of 'actualisation' (referred to as 'instantiation' - see, e.g. Halliday (1991)) is inherent in the notion of the system network: each instance of language, each 'act of meaning' is interpreted as a specific path through a network. What Halliday is saying, in his answer to Thibault's question, is that in a model which views language as a meaning potential, it is not necessary to have a separate component of 'language in use', since the potential, or the system, indicates what can be instantiated. ${ }^{9}$

\subsection{Typology and language universals}

Compared to other functional models (as we will see below, §§4-5), SFG has never had a strong typological orientiation. Although Halliday's first linguistic model was based on a description of Chinese (Halliday ), the major influential writings in SFG and especially those publications that form the key points in developing the design of the theory - have always, up to the present day, been based largely on English, leading to a particular 'imbalance' that Halliday (1993: 4506) himself recognises. However, especially since the 1990s, the model has been applied to languages other than English (e.g. Martin 1995), and there is a growing awareness that it is necessary to incorporate more typologically different languages into the description in order to

\footnotetext{
${ }^{9}$ For a more detailed account of the relationship between Halliday's model of language and the theory of pragmatics, see Butler (1988).
} 
refine the model. An example of this is the recent publication of Language Typology: A Functional Perspective (Caffarel et al. (eds.) 2004).

As a consequence of the lack of an inherently typological orientation, language universals as such have not played a major role in SFG. Halliday (1961) makes a distinction between a general theory of language and descriptions of particular languages on the other hand. Many aspects of SFG have been presented as 'general' aspects, such as the metafunctions themselves, the different modes of expression, the relationship between system and structure. Halliday expects certain of these 'general' aspects to be universal (e.g. the metafunctions - cf. Halliday 1994: xxxiii-xxxiv), but the notion of language universals is not further explored.

\section{Layering in Role and Reference Grammar}

\subsection{An overview}

The twin pillars on which RRG rests are (i) a model of semantic predicate/argument relations and (ii) a layered structure for the clause (LSC) which, although itself involving syntactic units, is semantically motivated. ${ }^{10}$ Clearly, we are primarily concerned here with the second of these components, but since the two are intimately related within the overall theory, and since the postulation of parallel semantic and syntactic structures could itself be seen as a kind of layering, we shall outline the semantic model very briefly before describing the layered structure of the clause.

The semantic structure of the clause is based on a system for the lexical decomposition of predicates derived from that of Dowty (1979), which in turn was based on the work of Vendler (1967/1957]). This semantic structure is presented in the form of a LOGICAL STRUCTURE (LS) in which complex lexemes are decomposed into more basic ones, through the use of operators such as BECOME and CAUSE. Six classes of predicates are recognised, each characterised by means of values of a set of four features, as shown in Table 3 (Van Valin 2005: 33):

\footnotetext{
${ }^{10}$ We shall not go into the historical development of the theory (for the main stages, see Foley and Van Valin 1984, Van Valin 1993, Van Valin and LaPolla 1997), but will concentrate on the latest version as presented in Van Valin (2005).
} 


\begin{tabular}{|l|c|c|c|c|}
\hline Predicate class & static & dynamic & telic & punctual \\
\hline State & + & - & - & - \\
Activity & - & + & - & - \\
Achievement & - & - & + & + \\
Semelfactive & - & \pm & - & + \\
Accomplishment & - & - & + & - \\
Active & - & + & + & - \\
accomplishment & & & & + \\
\hline
\end{tabular}

Table 3: Predicate classes in RRG

Static predicates represent states of affairs which do not involve 'happening'; dynamic predicates express actions; telic predicates represent states of affairs which involve an inherent end-point; punctual predicates encode events which effectively occur instantaneously. These features can be probed by means of a battery of tests (see Van Valin 2005: 35-41). Each class has a characteristic pattern in its LS, as can be seen from the examples below:

(7) Bernice was tired. (BNC HTY 2826)

tired' (Bernice) [state]

(8) Miss Cress watched her, ... (BNC AD1 1859)

do' (Miss Cress [watch' (Miss Cress, her)]) [activity]

(9) The glass shattered. (BNC CKB 0653)

INGR shattered' (glass) [achievement]

(10) Blue lights flashed. (BNC HTH 1763)

SEML do' (blue lights, [flash' (blue lights)]) [semelfactive]

(11) Alfred Oliver had died. (BNC ANK 0391)

BECOME dead' (Alfred Oliver) [accomplishment]

(12) They walked to the end of the road ... (BNC BN1 1082)

do' (they, [walk' (they)] \& BECOME be-at' (end of the road, they) [active accomplishment]

Note that although semelfactives and achievements are both punctual processes, they differ in that only achievements result in a change of state. Note also that active accomplishments are activities which result in a change of state and so are telic. Each of these basic types also exists in a causative variant. Two examples are given below: 
He opened it slowly ... (BNC EF7 569).

[slow' (do' (he, Ø))] CAUSE [BECOME open' (it)] [causative accomplishment]

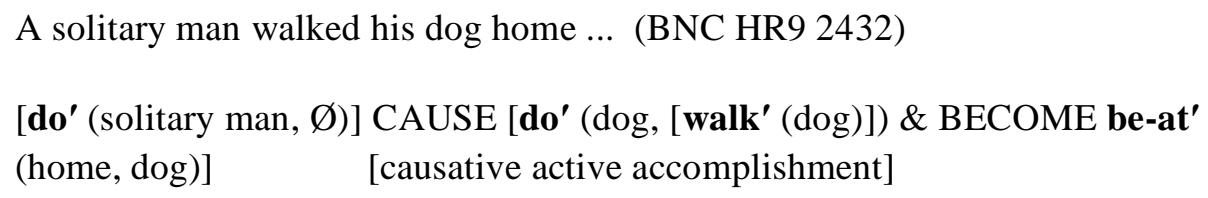

It is important to realise that elements such as watch', shattered', flash', dead', etc are intended merely as placeholders for an eventually more detailed system of lexical decomposition (for further detail see Van Valin and Wilkins 1993, Van Valin and LaPolla 1997: 116-118, Mairal Usón and Faber 2002).

Two further important characteristics of the semantic structures proposed in RRG should be mentioned. Firstly, thematic roles such as Agent, Patient or Theme are not regarded as primary elements of the theory, but are defined in terms of the positions for arguments in the decomposed semantic structure. Thus, for example, the sole argument of a 1-place stative predicate is the PATIENT, the first argument of a pure location predicate is a LOCATION and the second a THEME, the first argument of a cognition predicate is a COGNIZER (itself a type of EXPERIENCER) and the second the CONTENT, and so on. Secondly, specific thematic relations are grouped together under two semantic MACROROLES, the actor and undergoer, the former being the most agent-like and the latter the most patient-like. These macroroles are important because for some purposes particular thematic roles are treated by the grammar as essentially the same. Actor and undergoer are thus the two chief arguments of a transitive predication, and either one can act as the sole argument of an intransitive predication.

We now turn to the main topic of this section, namely the layered syntactic structure of the clause. This concept of clause structure, which goes back to the work of Foley and Van Valin (1984), partitions the clause into a CORE and a PERIPHERY. The core contains a NUCLEUS and core argument(s); the periphery contains adjuncts. In (16) is shown the layered structure of the clause in (15)

(15) Gareth ate everything fast. (BNC ADY 1079) 
(16)

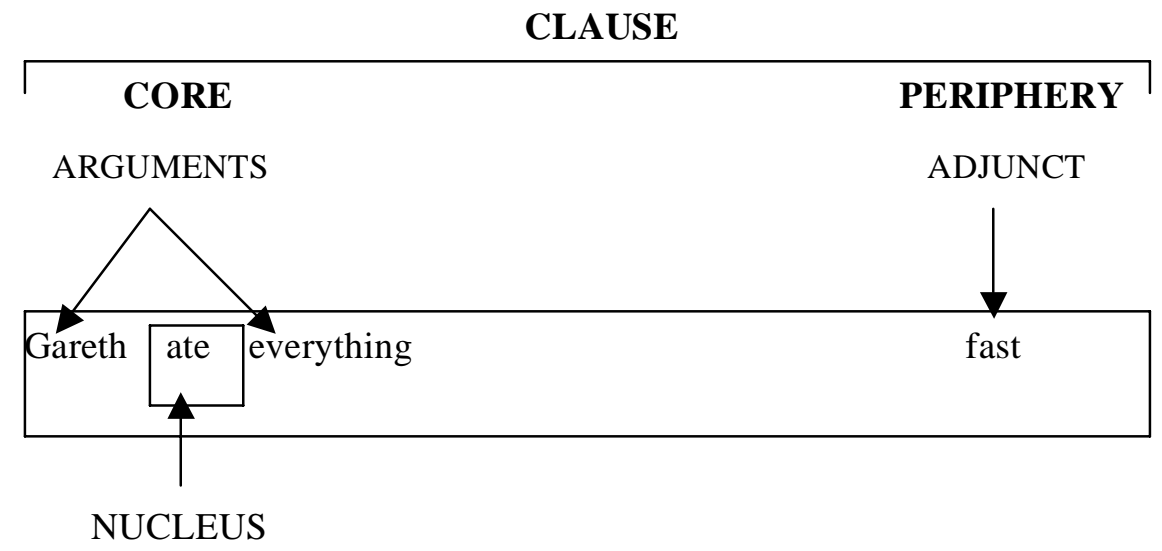

The units nucleus, core and periphery are syntactic, but are semantically motivated, in that the nucleus houses the semantic predicate, the core syntactic arguments are arguments in the semantic representation of the predicate, the core consists of these arguments plus the predicate, the periphery contains elements which are not semantic arguments of the predicate, and the whole clause contains the predicate, arguments and non-arguments.

The syntactic units can occur in any order which a particular language permits, so that this model of clause structure is equally applicable to both configurational language such as English and non-configurational languages such as the Australian Aboriginal language Dyirbal, which has very free word order.

The division into core, with its nucleus, and periphery is seen as universal. There are, however, other elements which occur in some languages but not others. In front of the core there may be a PRECORE SLOT (PrCS), which is the position in which topicalised (fronted) elements appear, and in which wh-words are placed in languages such as English, where they are not kept in their normal pattern position. Examples from English are given in (17) and (18), where the elements in the PrCS are in bold type:

This one I'm sure you'll recognise. (BNC JK2 326) What did you leave behind? (BNC ASN 1838)

In some languages there is a POSTCORE SLOT after the core. Left-dislocated elements occur in the LEFT-DETACHED POSITION (LDP), which is separate from the clause itself, although it is a constituent of the sentence. An example from English is given in (19): 
(19) As for him, his heart was still set on finding the sea-king's palace

(BNC FUB 0043)

Some languages also have a RIGHT-DETACHED POSITION, to the right of the clause proper. An English example is shown in (20):

(20) She is cunning, that girl. (BNC HTX 2807)

The structural elements of the clause are shown in the form of a CONSTITUENT PROJECTION. To this is added an OPERATOR PROJECTION which indicates the various operators, such as tense and illocutionary force, which modify particular layers, as shown in 0 for the one-clause sentence in (15).

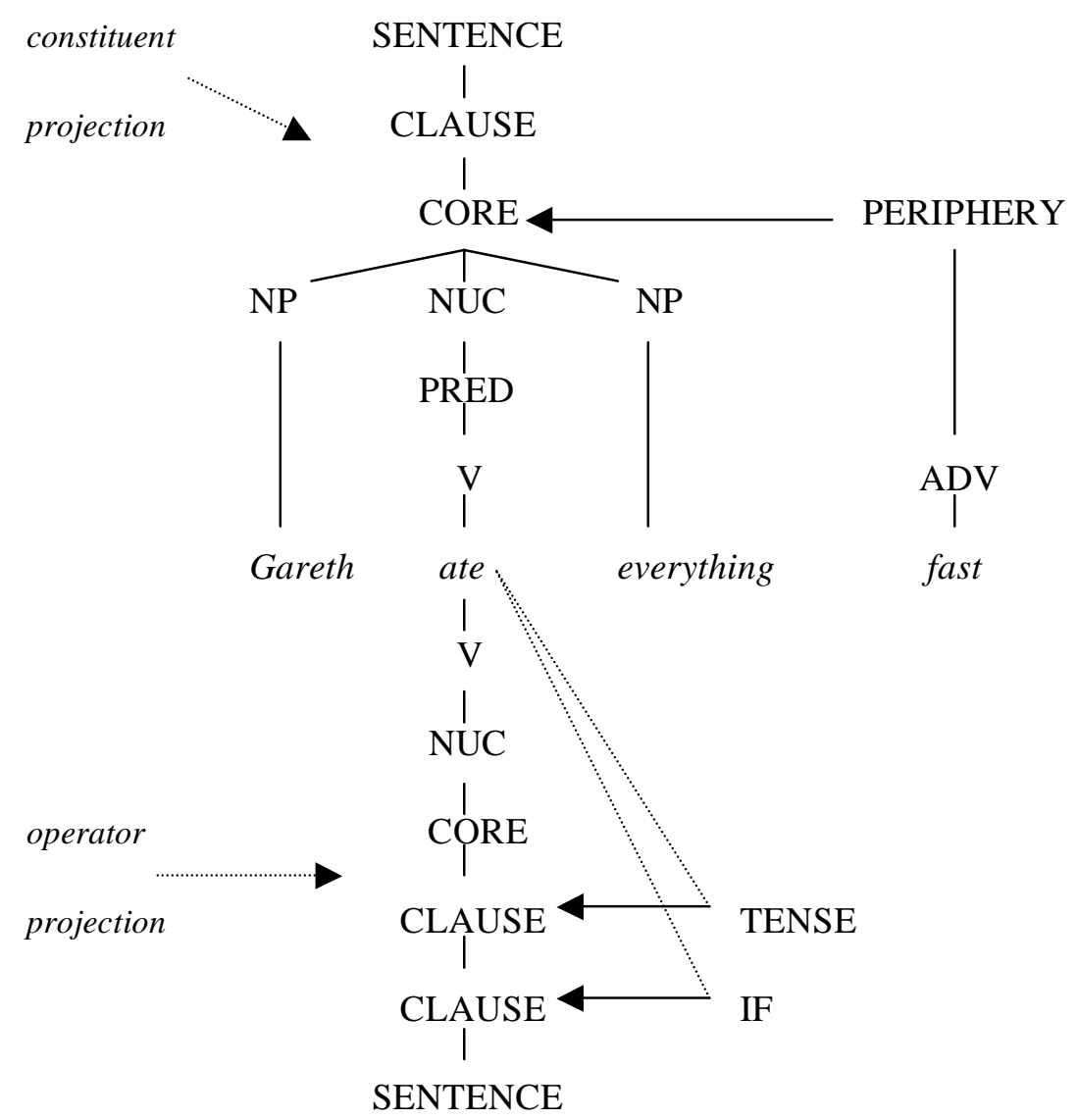

The operator projection shows that although illocutionary force and tense both modify the clause, the former has scope over the latter. Other clausal operators include evidentials and status (epistemic modality, external negation). Core operators include internal (narrow scope) negation, root modality, event quantification and those directionals which express the orientation or motion of one participant in relation to 
another or to the speaker (e.g. hin and her in German). Nuclear operators include those for aspect, lexically derived negation (e.g. unhappy in English) and those directionals which express the orientation of an action or event with no reference to its participants.

A third projection, the FOCUS STRUCTURE PROJECTION, represents aspects of the information structure, for which RRG took over, with some modifications, the theory elaborated by Lambrecht $(1986,1994)$, who analyses the information status of referring expressions in terms of the discourse-pragmatic functions of TOPIC and FOCUS. The topic is defined as the entity which the sentence or proposition is about, while the focus is that information which is asserted in a declarative or questioned in an interrogative, and is the most salient part of the utterance. The focus structure thus partitions the sentence into non-presupposed, focal material and pragmatically presupposed, non-focal elements. Languages may express focus by various means, including prosody, constituent order and focus-marking morphemes. ${ }^{11}$ For any given language, there is a POTENTIAL FOCUS DOMAIN (PDF), which must fall within the scope of the illocutionary force operator, and within which the ACTUAL FOCUS DOMAIN (AFD) for a given sentence must fall. The focus projection shows both domains, as illustrated in (22), which represents the interpretation of (15) in which the intonational prominence falls on fast and the whole of ate everything fast is the nonpresupposed, focal information, while Gareth, the topic, constitutes presupposed information (IU represents the basic information units).

\footnotetext{
${ }^{11}$ For details of the taxonomy of focus types in RRG, adapted from Lambrecht's work, see Van Valin (1993: 25-27, Van Valin and LaPolla (1997: 206-210). For a critical comparison of the treatment of focus phenomena in RRG, FG and SFG, see Butler (2005c).
} 


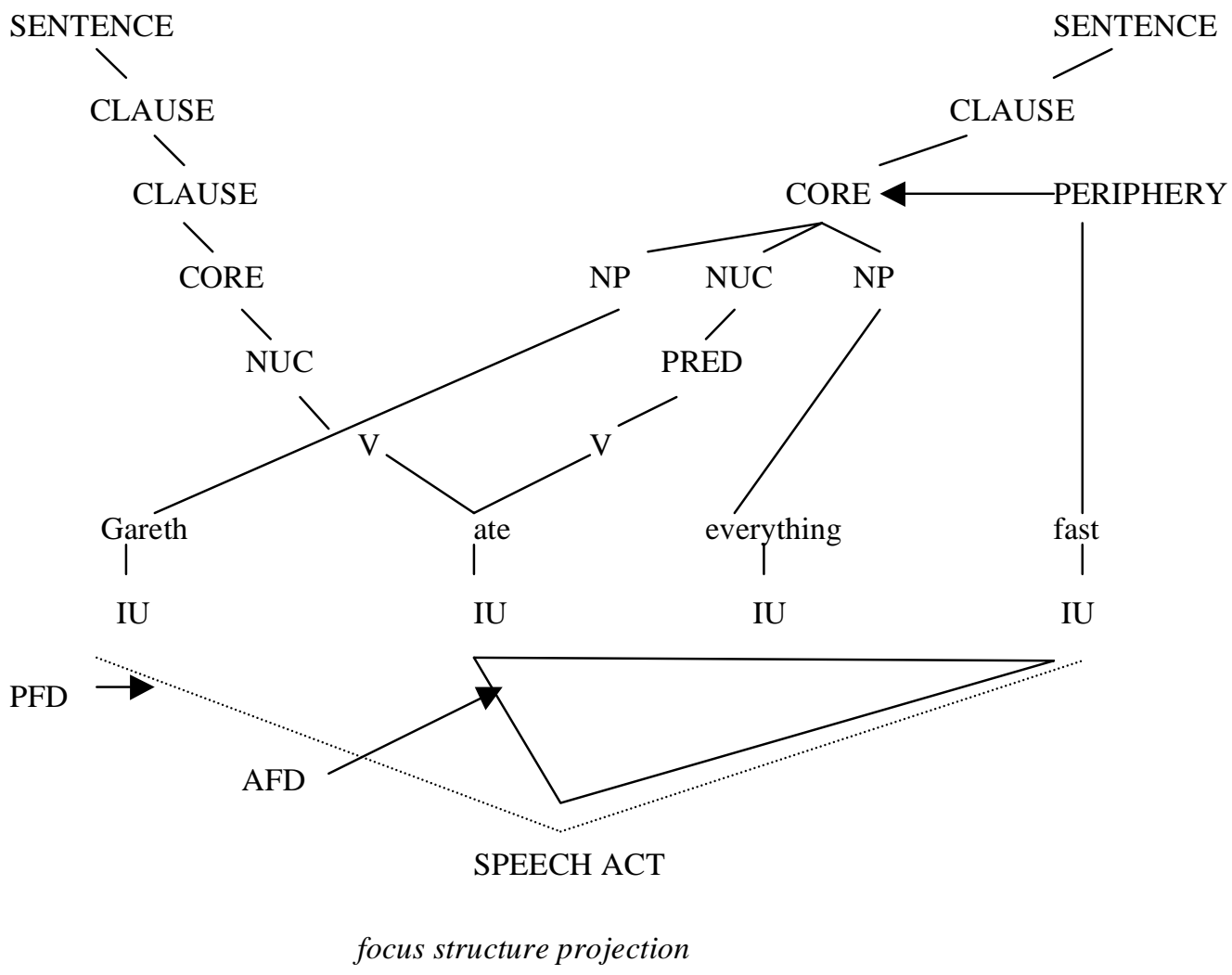

We have assumed up to now that only the core can take a peripheral adjunct. In recent work in RRG (Van Valin 2005: 21) it is recognised that adverbs can modify each layer in the structure, and as they act as adjuncts at that layer, it is proposed that each layer (nucleus, core, clause) has its own modifying periphery, rather than that there is a single periphery modifying the core.

It has been recognised for a considerable time that there are close parallels between the structure of clauses and that of noun phrases (see also §5.1; Rijkhoff, this volume). This similarity is reflected in the structure proposed for the NP in RRG. This consists of a core containing the nucleus and possible modifying prepositional phrases, and a Noun Phrase Initial Position (NPIP) which is structurally parallel to the PrCS in clause structure. Like the clause, the NP also has a set of operators modifying each layer of the structure. Van Valin (2005: 24) takes these from the work of Rijkhoff (2002): operators working at the level of the NP itself are concerned with definiteness and deixis, those at the core level with number, quantifiers and negation, and those at the nuclear level with nominal aspect (the count/mass distinction, classifiers). An example of a complete NP structure is shown in (23) 

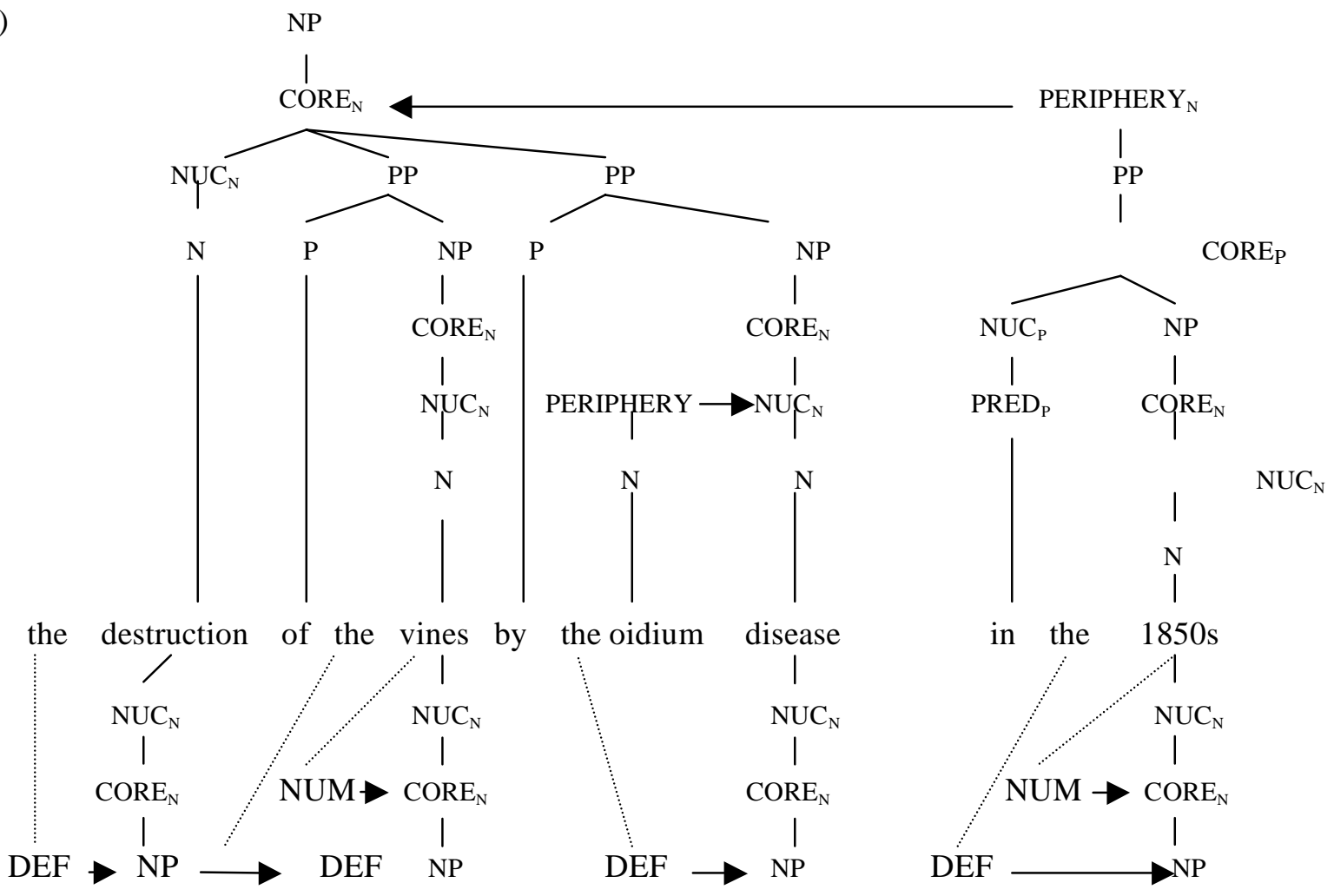

Finally, we should note that present-day RRG postulates detailed rules for mapping from semantic structures to syntactic structures (needed in modelling language production) and from syntactic structures to semantic structures (needed for comprehension). Lack of space precludes discussion of the complex details of the cross-linguistically tested linking algorithms here: details can be found in Van Valin (2005: Chapters 5 and 7), and a briefer treatment in Butler (2003a: 143-48; 2003b: 241-259).

\subsection{Evidence for layering}

Foley and Van Valin (1984), in the first major presentation of RRG, adduce three main types of evidence for the recognition of the nucleus, core and periphery within the LSC: the fact that (sets of) operators can be shown to affect only part of the total layered structure; the coding and behavioural properties of the units; and the crucial role of the layered structure in the explanation of clause linkage patterns. Let us examine each of these in turn. 
Firstly, as we have seen, there are operators, such as aspect and certain kinds of directionals, which affect only the event/state itself, independently of the rest of the core, i.e. the core arguments. Foley and Van Valin (1984: 79) cite this as part of the evidence for the recognition of the nucleus as a distinct unit within the clause. We might similarly point out that modality, as defined by these authors, "characterizes the speaker's estimate of the relationship of the actor of the event to its accomplishment, whether he has the obligation, the intention, or the ability to perform it" (Foley and Van Valin 1984: 214), and so affects both the predicate-containing nucleus and an argument of the predicate, but without any reference to other possible elements within the clause, so providing evidence for the core as a unit.

Secondly, there is, as Foley and Van Valin (1984: 79) observe, a wealth of evidence for the core/periphery distinction both from the ways in which these units are coded and from their syntactic behaviour in different languages. They point out that whereas, cross-linguistically, core arguments usually have unmarked morphological or syntactic forms, peripheral elements are often coded by means of marked forms, frequently adpositional. This is the case, for example, in English, where NPs acting as core arguments (the traditional subject and object) are coded non-obliquely, but peripheral elements obliquely, through the association of a preposition with the NP. Furthermore, in languages which have cross-referencing on the verb, usually only core arguments are involved. Again taking English as an example, the only argument which shows agreement with the finite verb is the subject, a core argument. The following examples are from the Australian language Gooniyandi, and are taken from McGregor's (1990) corpus of that language:

(24) (= McGregor's 3-41, 1990: 158)

girili waraari ngilanggoowa

tree it-stands eastern-end

'The tree stands on the eastern end (of a row of trees).'

(25) $\quad$ (= McGregor's 3-37, 1990: 156)

ngamoo nganyi marlami -ya ngaragbiddi boojabij

before me nothing LOC they-made-it post-office

'Before my time they built the old post office.' 
While the arguments girili in (24) and boojabij in (25) are cross-referenced on the verb, the adverbial nglianggoowa in (24) and the appositional complex of adpositional phrase and temporal adverbial in (25) are not.

In languages where coding properties do not themselves distinguish between core and peripheral elements, the syntactic behaviour of these elements may provide evidence for the recognition of the two layers. For instance, Foley and Valin (1984: 80) point out that in German, although the nominative case NP is unmarked, this does not apply to either accusative or dative NPs, neither do these NPs agree with the verb. However, only the accusative NPs in the active voice can become the nominative subject of a passive: even in cases where a verb (e.g. helfen, 'help') takes an object in the dative case, this object cannot become the subject of a passive. The ability to be a subject is taken to be a central property of core arguments.

Now let us turn to the distinction between the core and the whole clause. Van Valin (1990: 204-207) cites evidence from Icelandic and some other Germanic languages, in which, except in polar questions, the finite verb must come in second position in the clause. This means that if there is a topicalised NP or a preposed adverbial, inversion of the subject and finite verb is obligatory in order to keep the latter in second position, as in the German example in (26), the version in (27) being ungrammatical:

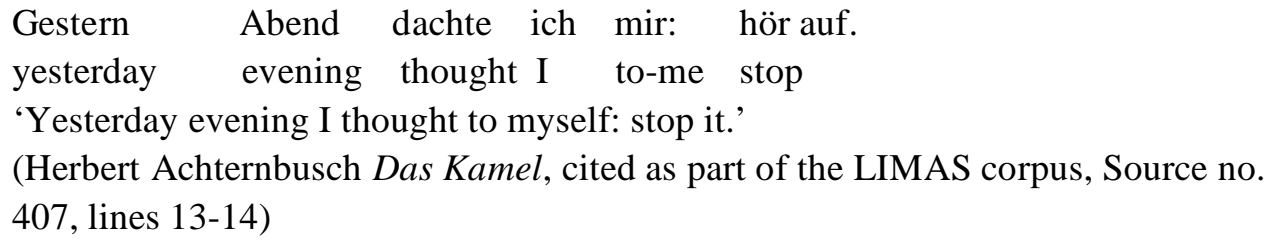

*Gestern Abend ich dachte mir: hör auf.

These syntactic facts can be accounted for in RRG by saying that the finite verb must be in second position in the CLAUSE (except in yes-no questions), and that the subject (or rather, the PSA in RRG) is the initial non-verbal constituent of the CORE. A phrase in the LDP or a complementiser, however, does not trigger inversion, showing that these are outside the clause itself. 
A second argument (Van Valin 1990: 207-213) comes from clause structure in typologically different kinds of language. Nichols (1986) proposes a typologicallyrelevant distinction between DEPENDENT-MARKING LANGUAGES, such as English and German, where the head-dependent relationship is marked on the dependent element, and HEAD-MARKING LANGUAGES, such as Lakhota and Jacaltec (Mayan), in which this relationship is marked on the head. In German, for example, the relationship between a verb and its object is marked on the object, by means of the appropriate case. In a head-marking language, on the other hand, predicate-argument relations are marked on the predicate itself. We saw earlier that in the Australian language Gooniyandi external arguments of the verb are cross-referenced on the verb itself (see examples (24) and) (25). In (28) is shown a further example from McGregor's Gooniyandi corpus (ERG represents ergative case, $\mathrm{CL}$ a classifier element):

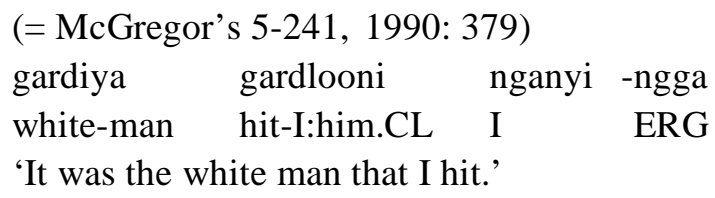

Crucially, the arguments nganyingga and gardiya can be omitted, leaving just gardlooni (see McGregor 1990: 200). Van Valin takes omissibility of this kind this to indicate that the true core arguments in head-marking languages are those attached to the predicate, while the other, omissible expressions are core-external, though clauseinternal.

A further important source of evidence for all the distinctions made in the layering model arises from the RRG theory of clause connection. Clause linkage, in the account of Foley and Van Valin and in all subsequent accounts, is modelled in terms of two interacting dimensions: JUNCTURE and NEXUS. Juncture refers to the layer involved in a connection between two clauses, and the hypothesis is that "a token of any layer - nuclear, core, or peripheral - may be joined to any other token of its same type" (Foley and Van Valin 1984: 188). Nexus refers to the type of linkage between clauses. In addition to the traditional categories of COORDINATION and SUBORDINATION, RRG recognises a third type of linkage, COSUBORDINATION, originally proposed by Olson (1981). A clause linked by coordination is neither embedded in another clause nor dependent on it; one linked in a subordinate 
relationship is both embedded and dependent; while a clause linked in a cosubordinate relationship is not embedded in the other clause, but is dependent in the sense that the two 'juncts' share at least one operator. ${ }^{12}$ Although the traditional terms 'coordination' and 'subordination' are used in this classification of nexus types, the definitions are quite different from those in traditional grammar: coordination is the relevant label only if the juncts are not related as part to whole, and do not share any operators at the appropriate level of juncture; subordination is appropriate only when one junct can be shown to be embedded in the other. In particular, Foley and Van Valin (1984: 243) warn that coordination must be carefully distinguished from conjunction, which is only one of the ways in which this relationship may be expressed. The combination of three levels of juncture and three nexus types predicts that nine different types of linkage will be found in the world's languages. In Foley and Van Valin (1984: 256) it is stated that nuclear subordination is not attested; however, Van Valin and LaPolla (1997: 458-459) give the example of verbs used as aspect operators in serial verb constructions in languages such as Barai (Papua New Guinea). Most languages have only a subset of the nine logically possible combinations (English has seven), though according to Yang (1994), Korean has all nine.

In addition to these nine possibilities, Van Valin and LaPolla (1997: 469) discuss briefly an additional linkage type, SENTENTIAL COORDINATION, in which the juncts are two whole sentences, one or both of which contain an element in the LDP, as in (29), where the second junct begins with the left-dislocated element as for the tiny cakes:

(29) Eline was almost too excited to drink the hot sweet tea and as for the tiny cakes, she knew she would never force one down, ... (BNC FRP 2194)

In the latest account of RRG (Van Valin 2005: 194), it is proposed that just as PPs in the periphery modify the core, so do those adverbial clauses which are the objects of predicative prepositions such as after or before, ${ }^{13}$ this type of linkage begin labelled

\footnotetext{
${ }^{12}$ Non-subordinate core junctures also involve the obligatory sharing of an argument: for details, see Van Valin and LaPolla (1997: 468), Van Valin (2005: 190).

${ }^{13}$ Note that RRG, in common with some other approaches, treats such items as prepositions taking a clause as their object, so differentiating them from true subordinating conjunctions such as because.
} 
AD-CORE SUBORDINATION. On the other hand, it is argued that adverbial clauses which are not introduced by predicative adpositions, for instance those with because, are not in the periphery of the core, but in that of the clause. This is termed AD-CLAUSAL SUBORDINATION. Some languages, e.g. Lakhota, also show AD-NUCLEAR SUBORDINATION. Ad-nuclear, Ad-core and Ad-clausal subordination are brought together under the label PERIPHERAL SUBORDINATION, while the type in which the subordinate junct is daughter of a higher node is called DAUGHTER SUBORDINATION.

A further development in Van Valin (2005: 192) is that a further linkage type, SENTENTIAL SUBORDINATION, is recognised. This occurs in examples such as (30) below, from Spanish, a language which, especially in its spoken form, makes much use of left dislocation. Here, we have a preposed adverbial clause cuando le conocí ('when I met him') which has its own LDP yo (I), and so constitutes a sentence, which is subordinated to the matrix sentence.

$$
\begin{aligned}
& \text { Bien, yo cuando le conocí, pues la verdad es que no hablaba ni una sola } \\
& \text { well I when him I-met well the truth is that not he-spoke not a single } \\
& \text { palabra, ... (CREA, interview Radio, Madrid y Candeleda, pueblo de Ávila, 24/09/91) } \\
& \text { word } \\
& \text { 'Well, when I met him, well he really didn't even speak a single word, ...' }
\end{aligned}
$$

So far, we have dealt only with the evidence for the units of the LSC themselves, as set out in the constituent projection for a sentence. We have also seen, however, that associated with each level of unit there is a set of operators, and that unlike the syntactic units themselves, as seen in present-day RRG, the operators are in a purely hierarchical arrangement, in which outer operators have scope over inner ones. Convincing evidence for the correctness of this scheme is the fact that the scope relationships proposed are mirrored in the order of realisation of the operators, across a wide range of languages. For instance, in languages, such as Kewa (Papuan) and the Australian language Tiwi, in which aspect (nuclear) and tense (clausal, or in early accounts peripheral) are expressed as separate inflections, aspect always occurs closer to the verb stem than tense. Van Valin (1993: 8; 2005: 10) cites the example from Turkish shown in (31), where the order of realisation of the operators, suffixed to the verb, is modality (not able), status (possible), tense (aorist): 
Gel- emi- yebil- ir -im come neg.able poss aorist $1 \mathrm{sg}$

An example from English is given in (32):

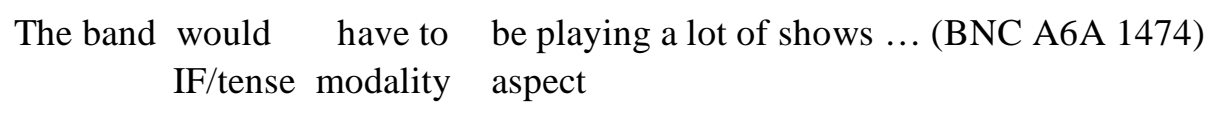

Clearly, such ordering can only be established when the realisations of operators all occur either before or after the verb. In the languages surveyed in Foley and Van Valin (1984) and in Bybee (1985), no counter-examples are found to the hypothesis concerning scoping and order.

Detailed accounts of all the evidence summarised in this section may be found in Van Valin and LaPolla (1997) and Van Valin (2005).

\subsection{The relationship between layering and the levels of syntax, semantics and pragmatics}

We have seen that the units in the layered structure of the clause, nucleus, core, periphery and clause, are motivated in SEMANTIC terms: the nucleus contains the semantic predicate, the core contains both the predicate and its arguments. They themselves are nevertheless not semantic but SYNTACTIC units, postulated in order to account for the types of morphosyntactic phenomena attested in the world's languages. For instance, there are instances of nuclei which contain not only a verbal predicate but also an incorporated noun (e.g. in Lakhota and Greenlandic Eskimo), and other constructions in which the core contains a syntactic argument which does not correspond to a semantic argument of the predicate in the nucleus (e.g. raising constructions of the type Bill seems to have crashed the car, where Bill occurs in the core Bill seems although it is not a semantic argument of seem) (see Van Valin and LaPolla 1997: 28-29, Van Valin 2005: 8). 


\begin{tabular}{|c|c|c|}
\hline Strongest syntactic linkage & Closest semantic linkage & English example of semantic linkage \\
\hline \multirow[t]{3}{*}{ Nuclear cosubordination } & Causative [1] & paint a table red \\
\hline & Phase & start $\mathrm{X}$-ing \\
\hline & Manner & enter a room skipping \\
\hline \multicolumn{3}{|l|}{ Nuclear subordination } \\
\hline Daughter & Motion & [not attested in English] \\
\hline Peripheral & Position & sit reading a book \\
\hline \multirow[t]{2}{*}{ Nuclear coordination } & Means & open sth by $\mathrm{X}$-ing it \\
\hline & Psych-action & decide to do sth \\
\hline \multirow[t]{2}{*}{ Core cosubordination } & Purposive & purposive infin clause \\
\hline & Jussive & ask/order $\mathrm{X}$ to $\mathrm{Y}$ \\
\hline \multirow{4}{*}{$\begin{array}{l}\text { Core subordination } \\
\text { Daughter }\end{array}$} & Causative [2] & force sbody to do sth \\
\hline & & \\
\hline & Direct perception & see/hear sbody o sth \\
\hline & Indirect perception & see/hear that sth is so \\
\hline \multirow{2}{*}{ Core coordination } & Propositional attitude & believe that \\
\hline & Cognition & know that \\
\hline \multirow{2}{*}{ Clausal cosubordination } & Indirect discourse & say that \\
\hline & Direct discourse & say + quote \\
\hline \multicolumn{3}{|l|}{ Clausal subordination } \\
\hline Daughter & Circumstances & after clause \\
\hline Peripheral & Reason & because clause \\
\hline \multirow[t]{2}{*}{ Clausal coordination } & Conditional & if clause \\
\hline & Concessive & even though clause \\
\hline \multirow[t]{2}{*}{ Sentential subordination } & Simultaneous actions & $\mathrm{X}$ and at the same time $\mathrm{Y}$ \\
\hline & Sequential actions & $\mathrm{X}$ and then $\mathrm{Y}$ \\
\hline Sentential coordination & $\begin{array}{l}\text { Situation-situation: } \\
\text { unspecified }\end{array}$ & $\mathrm{X}$ and $\mathrm{Y}$ (unordered) \\
\hline Loosest syntactic linkage & Loosest semantic linkage & \\
\hline
\end{tabular}

Figure 5: The Interclausal Relations Hierarchy

While the clause-internal elements are motivated semantically, those outside the clause, but within the sentence, are motivated PRAGMATICALLY: that is, they occur in constructions which are constrained in terms of pragmatic phenomena such as 
information structuring (Van Valin and LaPolla 1997: 39-40, Van Valin 2005: 8). For instance, fronting of a constituent so that it occupies the LDP or the PrCS does not alter the representational meaning of what is said, but rather serves to highlight that constituent in some way. ${ }^{14}$

RRG postulates an important relationship between the syntax of clause connection and the semantics type of the linkage. The INTERCLAUSAL RELATIONS HIERARCHY, which reflects the degree of tightness of the linkage, in both the syntax and the semantics, is shown in Figure 5, which is based on Van Valin (2005: 206-209).

The ordering of syntactic relations in the hierarchy is derived from the degree of (in)dependence of operators and the coding of semantic arguments as distinct core arguments, in the various types of linkage. At the tightest end, we have nuclear junctures, in which two nuclei behave as a single unit; at the loosest end, in clausal junctures each semantic argument occurs in a particular core, and the two clauses can choose their operator values freely; core junctures lie in between. Within each type of juncture, cosubordination is the tightest kind of linkage, since its defining characteristic is sharing of operators; coordination is the loosest type, with subordination in between.

The hierarchy of semantic relations is derived from the work of Silverstein (1976) and Givón (1980), who claim that semantic relationships can be classified according to the extent to which they represent different aspects of a single state of affairs, or two separate states of affairs. For instance, causation, also aspectual relations such as inception, continuation and ending, express two phases of one event, while temporal ordering expresses a relationship between two different events. It was also these authors who suggested that there is an iconic relationship between the semantic relationship and the syntactic form used to code it, although of course they were not operating with the syntactic categories of RRG: the hypothesis is that the tighter the semantic bond, the tighter the syntactic link used to code it. Clearly, there is no oneto-one relationship involved, as there are more types of semantic relation than of syntactic linkage. Also, we have seen that languages differ in the number of types of

\footnotetext{
${ }^{14}$ Compare SFG, where such 'fronting' is handled in terms of thematic choice, belonging to the textual component of the grammar.
} 
clause connection they allow, although all can express the various kinds of semantic relation. Thus even in a single language, one semantic relation may be coded by more than one type of syntactic link, and conversely one type of syntactic connection may code more than one kind of semantic relationship. Van Valin puts forward the following implicational universal constraint:

... while there is often more than one syntactic realization of a particular semantic relation, the tightest syntactic linkage realizing it should be tighter than the tightest syntactic linkage realizing looser semantic relations. (Van Valin 2005: 209)

This hypothesis makes testable predictions about types of relationship between semantics and syntax which should not be found: for instance, if in a particular language the tightest linkage that can realise a causative relation is core cosubordination, it should not be possible for a semantic type further down the hierarchy (say, a jussive relation) to be expressed by means of some kind of nuclear juncture. The fact that some languages code relations near the top of the hierarchy (e.g. causation) morphologically is fully consonant with the hypothesis, since morphology is an even tighter form of relationship than syntactic relations. Van Valin and Wilkins (1993) demonstrate that the Interclausal Relations Hierarchy allows the prediction, from the semantics of a complement-taking verbal predicate, of the type of syntactic linkage involved in complementation.

\subsection{Typology and language universals}

We have seen that RRG is strongly oriented towards a typological approach to language. Indeed, Van Valin has stated that the theory arose out of the attempt to answer the question

... what would linguistic theory look like if it were based on the analysis of Lakhota, Tagalog and Dyirbal rather than on the analysis of English? (Van Valin 1995: 461, 1996: 281) 
The layered model of the clause was developed precisely in order to solve the problems encountered by immediate constituent models when faced with nonconfigurational languages such as Dyirbal, and the evidence adduced for the model is drawn from a large number of languages, belonging to a wide range of typological groups.

The semantically-motivated elements of the LSC itself (nucleus, core, periphery, clause) and their relationships are claimed to be universal; on the other hand, the pragmatically-motivated elements (PrCS, LDP and RDP) are not universal. As far as the associated operators are concerned, the scoping between sets of operators is claimed to be universal, but there may be differences in the relative scope of operators within a given set (e.g. aspect/directionals at the nuclear level, types of status at the clausal level). Van Valin and LaPolla (1997: 40) make an interesting observation about the relationship between level of motivation and degree of cross-linguistic variation: the more semantic motivation there is for some grammatical phenomenon, the less cross-linguistic variation is attested, while the more pragmatically motivated phenomena show greater variation across languages.

\section{Layering in Functional Discourse Grammar}

\subsection{An overview}

Functional Discourse Grammar (henceforth FDG: Hengeveld 2004a, 2004b, 2005; Hengeveld and Mackenzie 2006, in preparation; Mackenzie and Gómez-González 2005) arose in response to criticisms of perceived deficiencies in its parent model, Functional Grammar (FG: Dik 1997a, 1997b). ${ }^{15}$ Dik proposed three standards of adequacy for $\mathrm{FG}:^{16}$

\footnotetext{
15 The 1997a account is an updated version of Dik (1989). An account of the development of Functional Grammar and the transition to Functional Discourse Grammar can be found in Anstey (2004).

${ }^{16}$ For further discussion of these standards of adequacy, see Butler (1991, 1999, 2003a: 64-67, 2003b: 454-465).
} 


\section{Pragmatic adequacy}

... a functional grammar must be conceptualized as being embedded within a wider pragmatic theory of verbal interaction. Ultimately, it would have to be capable of being integrated into a model of NLU [the Natural Language User - CSB]. We shall say that the degree of pragmatic adequacy of a functional grammar is higher to the extent that it fits in more easily with such a wider, pragmatic theory. (Dik 1997a: 13)

\section{Psychological adequacy}

... such a grammar must also aim at psychological adequacy, in the sense that it must relate as closely as possible to psychological models of linguistic competence and linguistic behaviour. (Dik 1997a: 13)

\section{Typological adequacy}

... A third requirement to be imposed on the theory of FG (in fact, on any theory of language) is that it should be typologically adequate, i.e., that it should be capable of providing grammars for languages of any type, while at the same time accounting in a systematic way for the similarities and differences between these languages. (Dik 1997a: 14)

It has been shown that despite its undoubted successes, Dikkian FG failed to achieve all three of these standards, although arguably typological adequacy was better served than the other two types. Butler (2003b: 454-465) reviews the arguments in relation to the model as a whole, while García Velasco and Hengeveld (2002) demonstrate that the central concept of the predicate frame in FG fails pragmatically, psychologically and typologically.

Furthermore, Dik's 1997 account contained only a rudimentary and programmatic discourse model, grafted on to the theory at a late stage, and it was left to others to 
develop a more detailed discourse grammar. ${ }^{17}$ Although there had always been an interest in discourse in certain FG circles, notably among the Anglicists at the Free University of Amsterdam and the Classicists at the University of Amsterdam, no overall model emerged. The beginnings of a new discourse-oriented model can be seen in Hengeveld (1997), where, following on from the work of Kroon (1995), an upward extension of the grammar into discourse is proposed, in the form of a RHETORICAL LEVEL, situated above the interpersonal level of the grammar, having variables for the discourse itself, the type of discourse and the moves of which it is composed. Around the same time, Mackenzie began to develop his Incremental Functional Grammar, which develops the structure of the discourse move in terms of its constituent acts and the subacts of which these may in turn be composed (see Mackenzie 1998, 2000). An important claim here is that holophrases, rather than being truncated versions of full utterances, are actually the basic minimal material out of which the more complex structures can be formed. In parallel with the work of Hengeveld and Mackenzie, other FG scholars were proposing modular schemes, ${ }^{18}$ in which separate pragmatic and grammatical components interacted in the formation of the final utterance.

Many of these developments have recently come together in the form of FDG. In presenting the theory, we shall adopt the latest version as outlined briefly in Hengeveld and Mackenzie (2006) and elaborated in much greater detail in Hengeveld and Mackenzie (in preparation). The theory combines the layering and modular approaches. Unlike its predecessor, FG, it is a TOP-DOWN model, starting with the communicative intentions of the speaker and ending with the sounds, written marks or other codes which transmit those intentions. This feature of FDG, which follows the proposals in Levelt's $(1989,1999)$ influential model of language production, is intended to allow greater psychological adequacy and is considered crucial to the development of a model of discourse.

\footnotetext{
${ }^{17}$ For a detailed survey of the various proposals which arose as a result of the movement towards a discourse-oriented FG, see Butler (2003b: 306-331).

${ }^{18}$ For a summary of these proposals, see Butler (2003b: 318-320).
} 
The components, operations and levels of representation in FDG are shown in Figure 6, adapted from Hengeveld and Mackenzie (2006: 669, 670). As can be seen from this figure, the overall model consists of four components: the CONCEPTUAL component, originally called 'cognition' (Hengeveld 2004a: 4, 9) is "the driving force behind the grammatical component as a whole" (Hengeveld 2005: 57). This component "is responsible for the development of both a communicative intention relevant for the current speech event and the associated conceptualizations with respect to the relevant events in the external real of imaginary world" (Hengeveld 2005: 57). The grammatical component is central to the overall model: indeed, the label FDG is sometimes applied just to this component, as when Hengeveld and Mackenzie (2006: 669) say that "FDG is the grammatical component of a wider theory of verbal interaction", so appearing to relegate the other components to the status of add-ons necessary in order to situate FDG itself within the framework of the communicative activity it serves. The CONTEXTUAL COMPONENT "contains a description of the discourse domain as it has been built up during the current discourse to the extent that this is relevant to the form that subsequent utterances may take. It does not only contain a description of the content and form of the preceding discourse, but also of the actual perceivable setting in which the speech event takes place" (Hengeveld (2005: 58). Finally, the OUTPUT component is concerned with the articulation of the phonological strings generated in the grammatical component, leading to the final expression. 


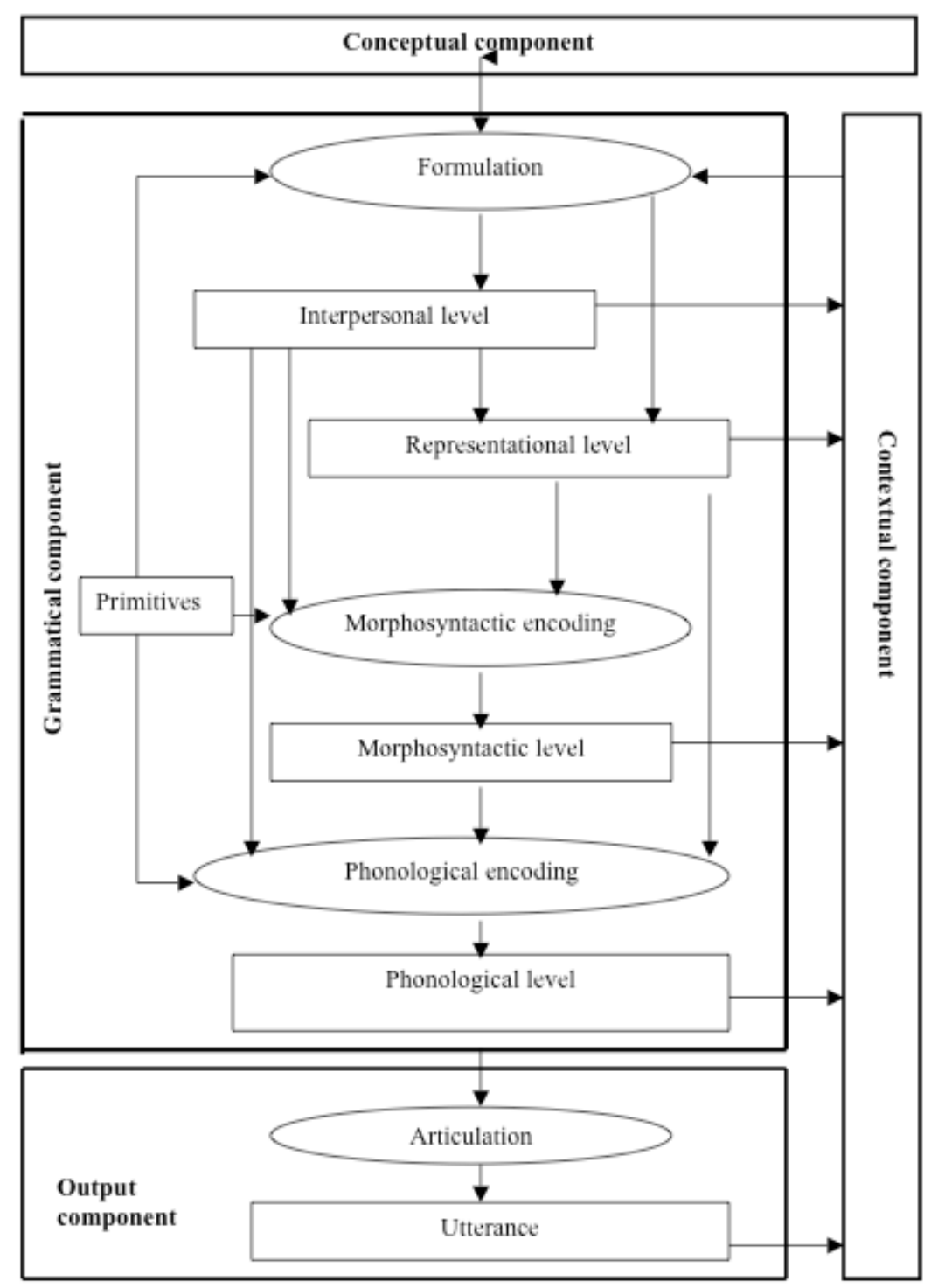

Figure 6: Components, operations and levels of representation in FDG (adapted from Hengeveld and Mackenzie 2006: 669, 670)

The top-down nature of the model can be seen in the flow of arrows from top to bottom of Figure 6: a message is generated by the conceptual component, and is converted, in the process of formulation, into a pragmatico-semantic structure which is in turn encoded into a morphosyntactic structure, and then a phonological structure, which is finally articulated.

The central grammatical component contains four levels: interpersonal, representational, morphosyntactic and phonological, as shown in Figure 6. As we saw in $\S 2$, the distinction between interpersonal and representational levels in FG dates back to the work of Hengeveld in the late 1980s, though we shall see later that there is 
an important difference between the original proposals and those of FDG. The introduction of a separate morphosyntactic level in FDG is a response to criticisms of the fact that FG lacked a clearly syntactic level of structure, the only mechanisms for syntax being the syntactic functions subject and object, introduced as a perspectivising device on completion of the predicational structure of the clause, and the rules for expression of the underlying clause structure in terms of word order and morphology (see Van Valin 1990, also the discussion in Butler 2003a: 206-209). Similarly, the phonological level, which is as yet not well developed within FG, responds to the need for a separate level of patterning at which the segmental and non-segmental aspects of the sound systems of language can be described.

There are systematic correspondences across all four levels of the grammatical component. Firstly, each is fed by a set of primitives, which always contains a subset with a structuring function and another subset of units with phonemic form; each also has a set of operators. Secondly, each level has a hierarchical layered structure which can be generalised as in (33) (Hengeveld and Mackenzie 2006: 671):

$$
\left(\pi \alpha_{1}:[(\text { complex }) \text { head }]\left(\alpha_{1}\right): \sigma\left(\alpha_{1}\right)\right)_{\varphi}
$$

where $\alpha_{1}$ represents a variable, restricted by a head (which may be complex), and also by one or more optional lexically-realised modifiers $(\sigma)$. There may also be further grammatical specification by means of an operator $(\pi)$ and/or a relational function $(\varphi)$.

With this general scheme in mind, let us now look in more detail at the interpersonal level, ${ }^{19}$ which "accounts for all the formal aspects of a linguistic unit that reflect its role in the interaction between speaker and addressee" (Hengeveld and Mackenzie 2006: 671). In other words, this level is concerned with the linguistic actions performed by the speaker, and with the rhetorical functions of discourse units. At this level, the speaker formulates a Move, consisting of one or more Acts; if there are several Acts, these are temporally ordered. Each Act, in turn, may contain a speech occurrence (e.g. an illocution), participants, and one or more Communicated

\footnotetext{
${ }^{19}$ The descriptions of the interpersonal and representational levels given here are based largely on Hengeveld and Mackenzie (2006, in preparation).
} 
Contents. Finally, each Communicated Content consists of Subacts which may be of two types, ascription and reference. Each type of unit, from Move down to Subact, may be further specified grammatically by means of operators and/or lexically by means of modifiers.

The Move is the largest unit relevant to grammatical analysis, but does not correspond straightforwardly to any one grammatical unit. A speaker's (or writer's) Move contains what s/he wishes to present as a coherent aspect of what is being talked about. It often corresponds to a turn in spoken discourse or a paragraph in writing. The discourse function of the Move is clearest in conversation, where it causes a reaction from the addressee, such as an answer to a question, an acknowledgment or a challenge. Moves may thus have the rhetorical function of Initiation or Reaction, or sometimes Feedback. (34) shows a simple example of a mini-conversation consisting of three moves:
A. what do you want
Initiation
B. I'd love one of those pears
Reaction
A. well have a pear
Feedback
(London Lund Corpus [LLC] 11 1a 50-52)

The move has a Head consisting of one or more acts. If there is more than one Act, the Acts may be independent of one another ('equipollent'), or they may be in a relationship of dependence. An independent Act which is in combination with a dependent Act has the rhetorical function Nucleus. Dependent Acts have rhetorical functions such as Motivation, Concession, Orientation, Correction. An example of a Move with two independent Acts is given in (35), while (36) shows an independent Act followed by a dependent Act:

I could not stop and I hit him.

$$
\text { Act } 1 \quad \text { Act } 2 \text { (LLC 12 14a 195-196) }
$$

(36) Be careful not to use treatments containing bactericides,

$$
\text { Act 1:independent ( Nucleus) }
$$

as these will render your filter useless.

Act 2: dependent (Motivation)

(BNC C97 2365)

Lexical modifiers indicate the role of the Move in the ongoing discourse. In (37), from a text about house buying, by the way, at the beginning of the third paragraph, 
signals a change of conversational (sub)topic from the general planning process to the materials needed.

And now, on with the hunt!

Where do I start? As with any important expedition, the best place to start is in the comfort of your own sofa, making a plan of campaign. The better your plan, the more likely you are to end up in the right place.

By the way, you'll notice that househunting involves large amounts of coffee, tea and paper. You'll have to supply the first two for now, but we have made a start with the paper work. (BNC AYP 110-115)

As yet, no grammatical operators for the move have been identified.

The Act is the smallest identifiable unit of communicative behaviour. There is no oneto-one correspondence between the discourse act and any syntactic unit, though there is a default correlation between acts and propositions. An Act will often be expressed, especially in spoken language, as a holophrastic expression, if the speaker considers that the content of such an expression is all that is required in at that point in the discourse, although much more complex Acts are, of course, possible. Two holophrases (Chocolate? Coffee.) are included in the excerpt from a conversation given in (38):

"What's that?" I ask lazily. "Chocolate?" “Coffee. I won't sleep now." (BNC J13 1006-1010)

Like other units, Acts have a Head and optional modifiers and operators. Consider example (39):

The structure for this Act contains a Head consisting of a speech occurrence (in this case a declarative illocution), two participants (Speaker and Addressee), and a Communicated Content containing two Subacts of reference (corresponding to she and the school) and one of ascription (left). There is a lexical modifier (luckily) showing the speaker's attitude towards the Communicated Content, and an operator 
(exclamative) intensifying the declarative illocution. The Act would also have a functional label showing how it fits into the Move of which it forms a part.

The obligatory speech occurrence of an Act can be either Expressive or Illocutive, Expressives (e.g. damn! ouch!) having no Communicated Content. A specific subclass of Illocutives is formed by Interactives (e.g. Congratulations! Thank you). The Head of the speech occurrence can be either an explicit performative verb or an abstract predicate such as DECLarative, INTERrogative, IMPERative, PROHibitive, etc. Lexical modifiers indicate the way in which a speech act is being made, as in (40), and operators can provide grammatical reinforcement or mitigation of speech act force, as with the Dutch particles dan and maar.

$$
\text { Honestly, I don't remember. (BNC CK4 0344) }
$$

In the structure of an Act, there is always a slot for the Speaker, and there may be one for the Addressee. There may be restrictive modifiers for participants, as in (41), and participants are also subject to operators for number.

Do you Paul, take this woman, Tori, to be your lawful wedded wife, ... http://www.panaga.com/wed/ceremony.htm

The Communicated Content within an Act must contain all that the Speaker wants to evoke in communicating with the Addressee. Its Head consists of one or more Subacts of reference (evoking an entity) or ascription (evoking a property). Every Communicated Content has a Subact which bears the pragmatic function Focus, i.e. a subact which is particularly salient and closely related to the communicative intention of the speaker. Three types of focus are recognised: New Focus, in which the information is presented as being new for the addressee; Emphatic Focus, asking for the addressee's special attention to one subact; Contrastive Focus, indicating a contrast between two sets of Communicated Contents or between one Communicated Content and contextual information. The three types of focus are independent of each other: indeed, all three can be present on the same subact. Each Communicated Content normally has only one New Focus, but can contain more than one Emphatic and/or Contrastive Focus. Focus can be expressed by means of intonation, constituent order, special words (e.g. Q-words such as who in English), special constructions (e.g. 
clefts) and special focus markers, according to the language concerned. In (42) focus is expressed intonationally (indicated by underlining) on the last constituent, while in (43) intonational prominence is combined with a cleft construction: so you have officially been given a new job (LLC 27 425) it was Serena who discovered that she'd got married (LLC 214 88)

In some languages, a non-Focus Subact may be marked with the pragmatic function Topic, indicating that the entity referred to already exists in the contextual component, and that further information about it will be given in the following discourse. It is argued that English does not have the Topic function, since there is no grammatical reflection of topichood in this language.

The Communicated Content may have a lexical Modifier, for example indicating that what is being communicated is not the speaker's own claims but those of someone else:

(44) $\quad \ldots$ the station commander was reportedly furious the next morning. (BNC AR8 0278)

In some languages, such 'evidential' status is indicated grammatically, e.g. by means of a suffix, rather than lexically. In such cases we have an operator (Reportative) acting on the Communicated Content.

Ascriptive Subacts, which as we have seen evoke properties, can have modifiers, as in (45), where as it were indicates that the speaker does not want to ascribe the property of being Pope and Patriarch unreservedly to Anselm.

(45) Urban II himself paid homage to this point of view when he introduced Anselm to the Curia as "one who is almost our equal, being as it were Pope and Patriarch of the alter orbis". (BNC CKR 1131)

Ascriptive Subacts may also take operators, for example to indicate approximation, as with kinda in (46): 
Referential Subacts, which evoke and entity, may take as Head a proper name, or an abstract specification such as $[+\mathrm{S},+\mathrm{A}]$ (indicating the inclusive first person plural we in English, for example), or one or more ascriptive Subacts. The last situation occurs in examples such as (47), where both yellow and powders represent ascriptive Acts: The yellow powders from some manufacturers are acceptable ... (BNC APV 0762)

Referential Subacts may have a Modifier at the interpersonal level, for example indicating the speaker's sympathy with the entity referred to, as with poor and old in (48):

Referential subacts also have operators for two different kinds of identifiability of the entity referred to: the speaker's assumptions about identifiability for the addressee, reflected in (in)definiteness, and identifiability for the speaker him/herself, reflected in (non)specificity. Examples are shown in

(49) The Government has thus done what no government before has done ... (BNC ASB 1216) [definite, specific, i.e. identifiable by speaker and assumed to be identifiable by addressee]

(50) Someone gave it to me. (BNC APM 1926) [indefinite, specific, i.e. identifiable by speaker but not identifiable by addressee]

(51) Who is your designer? (BNC ASC 0618) [definite, nonspecific, i.e. assumed identifiable by addressee but not identifiable by speaker]

(52) A woman might marry someone who reflects the emotional responses she had with her father. (BNC ARG 0274) [indefinite, nonspecific, i.e. not identifiable by speaker and assumed not to be identifiable by the addressee]

We now turn to the representational level of the grammatical component. This level "accounts for all the formal aspects of a linguistic unit that reflect its role in establishing a relationship with the real or imagined world it describes" (Hengeveld and Mackenzie 2006: 673). It is concerned with a set of entities and the relationships among them: the most basic categories are INDIVIDUALS, STATES OF AFFAIRS (SoAs) and PROPOSITIONAL CONTENTS; in addition, FDG recognises PROPERTIES, LOCATIONS 
and TIMES. Individuals are first order entities which can be located in space and evaluated in terms of their existence. States of affairs are second order entities, representing events, states, etc, which occur in a particular place and at a particular time; they can be evaluated in terms of their reality or unreality. Propositional contents are third order entities are potential facts which can be agreed or disagreed with, debated, or said to be true or untrue, and therefore cannot be located in either space or time; they can, however, be evaluated in terms of their truth. EPISODES are semantically-coherent sets of propositional contents. Properties have no existence independently of the entities they apply to, but can be characterised in terms of those entities: for instance, blue applies to first order entities, hit to two first order entities, imminent to second order entities, unbelievable to third order entities. Locations (e.g. top) and times (e.g. week) are self-evident.

These various types of entity are related in the following way. Episodes, as we have seen, contain sets of propositional contents. Propositional contents contain SoAs, which are in turn made up of predicates, representing properties, and their arguments, representing entities which can be of any type, depending on the predicate concerned. Some predicates (e.g. hit) take only first order entities (individuals) as arguments. Others can take second order entities (SoAs) as arguments (e.g. see, which can take 1st, 2nd or 3rd order arguments, as in see John, see John arriving, see that John has arrived). Others (e.g. believe) take third order entities.

Before we go on to examine the various units in more detail, there is one important difference between this account and those of earlier FG which should be mentioned. In Hengeveld's original proposals for the distinction between interpersonal and representational levels, the former embraced the propositional and the speech act layers of Dik's underlying clause structure, while the latter encompassed the predicate and predicational levels. In FDG, as we have seen, the propositional layer is moved into the representational level. One argument for this position (see Hengeveld and Mackenzie in preparation) is that propositional contents can be attributed to people other than the speaker (Bill believes that $X$ ), while everything at the interpersonal level is concerned with the acts (illocutionary, ascriptive, referential) which speakers perform, taking into account their assessment of the cognitive state of the addressee. 
An episode with a Head consisting of three independent semantically coherent propositional contents is shown in (53), and an episode with one indepdendent set of propositional contents and one dependent set in (54).

(53) He stayed for weeks, ran up astronomical phone bills, and then vanished. (BNC ASV 1644).

(54) They must have found it, because it was gone the day after. (BNC BN6 1676)

Episodes can be modified by items such as first(ly), second(ly), etc., to show their place in an even higher unit of discourse, as in (55).

For Dicey, the rule of law involved three propositions. First, it meant that "no man [was] punishable or [could] be made to suffer in body or goods except for a distinct breach of law established in the ordinary legal manner before the ordinary courts of the land". Secondly, it also meant "not only that no man [was] above the law, but (what is a different thing) that here every man, whatever be his rank or condition, [was] subject to the ordinary law of the realm and amenable to the jurisdiction of the ordinary tribunals. Thirdly, it involved saying that "the general principles of the constitution (as for example the right to personal liberty, or the right of public meeting) are with us as the result of judicial decisions determining the rights of private persons in particular cases brought before the courts." (BNC ASB 105-108)

Operators for the episode are uncommon, though they do exist: in German, for example, a whole stretch of language may be marked as reported, with the speaker taking no responsibility for its veracity, by the use of the subjunctive mood throughout.

Propositional contents contain a Head consisting of either one or more SoAs or a single word such as yes or no which encapsulates a whole proposition. An example of the former type is given in (56), in which the SoA concerned with the speaker missing the lecture is incorporated into a proposition which is entertained as probably true.

$$
\text { I probably missed that lecture. (BNC HNN 1158) }
$$

Note that propositional contents can take a modifier (here probably) indicating the speaker's degree of commitment (subjective modality). They can also take modifiers showing the source of evidence the propositional contents (e.g. visibly). Some 
languages indicate subjective and evidential modalities by grammatical means, i.e. operators over the propositional content.

SoAs, which as we have seen can be located in time and space, have a head consisting of the various types of entity which go to make up that state of affairs. In the simplest case, the components of the SoA are a property or relation and one or more individuals for which this property or relation holds, as shown in (57):

$\mathrm{He} \quad$ kicked the fallen easel.

individual property individual (BNC AEB 2294)

There are, however, many other possible types of structure, which may differ from one language to another. For instance, in (58) we have a property (cause) which takes two other SoAs as its arguments: 0491)

Languages differ in how many arguments they allow for their predicates and in the types of semantic arguments they permit.

In FDG the possible structures for SoAs in a given language are shown by means of PREDICATION FRAMES rather than in terms of the PREDICATE FRAMES of earlier FG which have been shown to be inadequate from pragmatic, psychological and typological viewpoints. Predication frames show the possible structures without reference to the lexemes that can fill them. The links between predication frame and lexeme are made through the lexical entry for the lexeme. A simple example of a predication frame for English, covering intransitive predicates such as swim or die, is shown in (59)

$$
\begin{aligned}
& \begin{array}{lll}
\mathrm{C} & \mathrm{T} & \mathrm{R}
\end{array} \\
& \left(\pi \mathrm{p}_{1}:\left[\left(\pi \mathrm{e}_{1}:\left[\left(\mathrm{f}_{1}\right) \quad\left(\tau_{1}\right)_{\varphi}\left(\mathrm{e}_{1}\right)\right)\right]\left(\mathrm{p}_{1}\right)\right)\right.
\end{aligned}
$$

where $\pi$ is an operator, $p$ the propositional content variable, e the SoA variable, $f$ the property/relation variable, $\tau$ a variable representing any kind of entity, $\varphi$ some 
semantic function, $\mathrm{C}$ the Communicated Contents, $\mathrm{T}$ an ascriptive Subact, and $\mathrm{R}$ a referential Subact.

SoAs can take lexical modifiers for time, place, frequency, reality status, cause and purpose; see the time and place modifiers in example (60):

$\begin{array}{llll}\text { I'll see you } & \text { here } & \text { tomorrow } & \text { at ten o'clock } \\ & \text { place } & \text { time } & \text { time } \ldots \text { (BNC ASN 2140) }\end{array}$

Operators over SoAs found in the world's languages include those for location (as in languages which indicate grammatically that the speaker was not present at the time something took place), tense, event quantification(e.g. habituality), event-oriented modalities of various types, and polarity. In (61), used to codes both past tense and habituality: He used to send me postcards from abroad ... (BNC AT1 0560)

We now turn very briefly to the morphosyntactic and phonological levels of the grammar. The first of these levels "accounts for all the linear properites of a linguistic unit, both with respect to the structure of sentences, clauses, and phrases, and with respect to the internal structure of complex words" (Hengeveld and Mackenzie 2006: 674). The various parts of the structure and their ordering are triggered by information from the interpersonal and representational components. An example is given in (62):

$$
\begin{aligned}
& \text { The linesman saw the incident ... (BNC E9P 0711) } \\
& {\left[\left[\left[[D @]_{\text {Det }}[1 \mathrm{aInzm} @ n]_{\mathrm{N}}\right]_{\mathrm{NP}, \text { Subj }}\left[[\mathrm{si} ;- \text { Past }]_{\mathrm{V}}\left[[\mathrm{D} @]_{\mathrm{Det}}[\text { InsId@nt }]_{\mathrm{N}}\right]_{\mathrm{NP}, \text { Obj }}\right]_{\mathrm{VP}}\right]_{\mathrm{Cl}}\right]_{\mathrm{S}}}
\end{aligned}
$$

Here, the default choice of active rather than passive voice, itself reflecting the (pragmatic) information status of the two referents in the discourse at this point, determines that the linesman will be the subject, and the incident the object. The subject NP-verb ordering is triggered by the illocutionary force operator DECL associated with the act at the interpersonal level. The presence of the definite determiner in each NP is triggered by the association of the operator value [definite] with each of the referential Subacts at the interpersonal level. The presence of the Past 
tense marker is a reflection of the choice of the tense operator value [Past] for the SoA at the representational level.

The final level in the grammatical component, the phonological, "accepts input from the Interpersonal and Morphosyntactic levels and provides input for the extragrammatical processes of articulation" (Hengeveld and Mackenzie 2006: 675). Phonological representations contain both segmental and suprasegmental (prosodic) information about the utterance. One possible reading of the example in (62) is shown in (63), where \# represents a morpheme boundary and large type represents the accented intonational nucleus, the symbol $\backslash$ indicating falling intonation. \#D@\#laInzm@n\#ISO;\#DI\#InsId@nt

Here, the position of accentual prominence reflects the fact that the ascriptive Subact realised as saw bears the focus. This decision is made at the interpersonal level in the light of the informational status of the various subacts in the discourse at this point: the 'incident' had just been mentioned, and the linesman is always available to participants in a discourse about particular types of game; the falling intonation (together with the word order mentioned earlier) is triggered by the DECL illocutionary force of the act, allocated at the interpersonal level. Note the conversion of the canonical phonological form of the definite article into [DI] before a word beginning with a vowel.

So far, we have been concerned only with layering in the clause. Although Dik (1989) recognises a number of types of 'term operator' (e.g. for (in)definiteness, specificity/ genericity, nearness/remoteness, quantification and ordination, as well as mensural and sortal classifiers), it was left to Rijkhoff $(1990,1992)$ to show that the layering principles already proposed for the clause could also be applied to the noun phrase (or 'term phrase'). Many of Rijkhoff's proposals were incorporated into the version of FG put forward in Dik (1997a, 1997b). In this early work, Rijkhoff distinguishes three layers within the NP, with operators and satellites at each layer. In Rijkhoff (2002) the three layers are expanded to four, and in Rijkhoff (forthcoming) to five. The fivelayer model is shown in (64) 
where subscripts 0 to 4 indicate the five layers, $\Omega / \omega$ represents a term (NP) operator and $\tau / \mathrm{T}$ a term (NP) satellite, f being a predicate variable symbolising the property represented by the head noun, and $\mathrm{x}$ a variable symbolising the referent of the noun phrase. Operators at layer 0 in this new model correspond to what in the earlier (2002) model were labelled as 'qualifying operators', specifying nominal aspect, i.e. the kind of thing (e.g. individual, collective) being referred to by the head noun; level 0 satellites relate to the classification of the type of entity represented by the head noun, as in electric train or social security. Both operators and satellites at level 0 take the core layer $\left(\mathrm{L}_{\mathrm{c}}\right)$ as their argument. There are now no operators at level 1, as indicated by the empty slot at this point in 4 ; level 1 satellites are concerned with more or less inherent properties of the referent normally expressed by adjectives in languages which have them. Level 2 houses operators and satellites concerned with quantity, i.e. number distinctions and cardinality. Level 3 accommodates operators and satellites which locate the referent in space and time. While levels 0 to 3 are descriptive, level 4 is concerned with the status of the referent in terms of the discourse itself, and so deals with definiteness and specificity and with notions of sameness, difference, etc.

Hengeveld (forthcoming), drawing on Rijkhoff's work, has presented a schema for the layered structure of the NP in FDG, as shown in (65)

$$
\begin{gathered}
\left(\Pi^{\mathrm{R}} \mathrm{R}_{\mathrm{I}}: \ldots \ldots \ldots \ldots \ldots \ldots \ldots \ldots \ldots \ldots \ldots \ldots \ldots \ldots \ldots \ldots \ldots \ldots \ldots \ldots \ldots \ldots \ldots\right. \\
\left.\left(\mathrm{R}_{1}\right): \Sigma^{\mathrm{R}}\left(\mathrm{R}_{\mathrm{I}}\right)\right) \\
\left(\pi^{\mathrm{x}} \mathrm{x}_{\mathrm{i}}:\left(\pi^{\mathrm{f}} \mathrm{f}_{1}: \operatorname{Lex}_{\mathrm{N}}\left(\mathrm{f}_{1}\right): \sigma^{\mathrm{f}}\left(\mathrm{f}_{1}\right)\right)\left(\mathrm{x}_{1}\right): \sigma^{\mathrm{x}}\left(\mathrm{x}_{1}\right)\right)
\end{gathered}
$$

where $\mathrm{R}$ operators/modifiers are concerned with situating the referential subact in the communicative situation, while $\mathrm{x}$ operators/modifiers relate to the properties of the set of entities designated, and f operators/modifiers are concerned with the characteristics of the property $\mathrm{f}$ itself. At the $\mathrm{R}$ level we have operators for identifiability and specificity, which are concerned with the speaker's assessment of how much the addressee knows about the referent, and also modifiers indicating subjective attitude; at the $\mathrm{x}$ level we have operators for location and number, and modifiers indicating referent modification; and at the f level the operators are concerned with shape and 
measure, and the modifiers with reference modification. ${ }^{20}$ A detailed comparison and critique of the Rijkhoff and Hengeveld proposals can be found in Butler (forthcoming).

\subsection{Evidence for layering}

Hengeveld and Mackenzie (in preparation) present two pieces of evidence for the distinction between interpersonal and representational levels of the grammar. Firstly, adverbs such as briefly or frankly can be used in two ways, as shown in the examples in (66) and (67).

(66) Very briefly, according to Prague linguists such as Mathesius and Firbas, the nature of interaction suggests that the usual, unmarked order of message segments is that of theme followed by rheme. (BNC FRL 1448)

(67) He glanced at her briefly, then reached for the bottle and topped up both their drinks. (BNC FS8 2885)

In the first case we have an interpersonal use, in the second a representational use. Since interpersonal elements are not concerned with the establishment of a relationship between language and the real world, but are internal to the speech situation, the clause in (66) cannot be reported indirectly (unless in 'free indirect speech'), whereas the representational use in (67) can:

(68) *The lecturer said that very briefly according to Prague linguists such as Mathesius and Firbas, the nature of interaction suggests that the usual, unmarked order of message segments is that of theme followed by rheme.

(69) Peter said that he glanced at her briefly, then reached for the bottle and topped up both their drinks.

Hengeveld and Mackenzie therefore suggest that the ability to be used in normal indirect speech contexts can be used as a test for representational as opposed to interpersonal elements.

A second piece of evidence for the interpersonal/representational split comes from the area of reference. As Hengeveld and Mackenzie point out, in examples such as (70),

\footnotetext{
${ }^{20}$ The distinction between 'referent modification' and 'reference modification' is taken from Bolinger (1967).
} 
expressions such as a bullet and a rock can be seen as referring expressions in two different ways: firstly, the speaker uses them to refer to particular entities in the world; secondly, the expressions themselves refer to entities of the class 'bullet' and 'rock' respectively. The first of these is what Hengeveld and Mackenzie refer to as EVOCATION, and involves an act of the speaker, so being interpersonal in nature, while the second is concerned with DENOTATION, and is representational. A bullet hit a rock three yards in front of him. (BNC H92 3088)

Crucially, the two aspects can be divorced from one another, as in examples such as (71), in which a cat denotes an animal of the feline class, but the speaker is not performing an Subact of reference, but rather one of ascription.

We now turn to evidence for the layered units proposed at the interpersonal and representational levels. We have seen that evidence for the distinction between Moves and the Acts of which they are composed can be adduced from the behaviour of these units in the discourse which to which they contribute: only a Move can be used to provoke some reaction from a co-participant, this being most clearly seen in conversation. In (72), for instance, it is the whole complex of the warning and the motivation for that warning which constitutes the Move and is expected to provoke an appropriate reaction in the addressee, the warning and motivation themselves being Acts within this Move:

$$
\begin{aligned}
& \text { Be careful, because they don't want to be in a thunder storm. (BNC KBW 00082) } \\
& \text { Warning } \quad \text { Motivation }
\end{aligned}
$$

In general, evidence for layered units comes from two main sources: scope phenomena and the overt marking of particular kinds of unit in some languages. We have seen that each unit at the interpersonal and representational levels in principle takes both lexical modifiers and grammatically-realised operators (though no operators have yet been found for Moves). The fact that it is possible to identify a scope over which each modifier and operator exerts its influence constitutes evidence 
for the units involved. For example, in (73) the adverb however takes in its scope all the material in the paragraph it stands at the beginning of, this being in contrast with the preceding paragraph, while in (74) the same adverb has as scope only the statement in which it is included. In the first case, however modifies a whole Move, in the second case merely an Act.

(73) The feature that makes it dreadful is that it is crammed with unattractive tourists throughout the summer months, shambling around 50 feet above sea level in a state of exhaustion, asking everyone if they're near the top yet. Perhaps it's mountain snobbery to wish to avoid such a crowd, and if so then I am a mountain snob. It's precious meeting the odd soul on a high top and passing the time of day with them, knowing that no matter who or what they are, you share the same interests in wildlife, wilderness and solitude. It's quite another thing to share a summit with 60 people who express disappointment that there is no hot-dog stand.

However, if those who successfully gain the top, with or without the burden of livingroom furniture, feel blessed with the exhilaration and wonder of their surroundings then I am happy for them, and glad they are able to share an emotion I regularly enjoy on the hills. It's merely that if there's more than 50 of them feeling it simultaneously on the same summit then I'd rather be somewhere else. (BNC AS3 0009-0114)

(74) In June 1937, a six-week ban on all political processions in a part of the East End of London was imposed. Over the years, however, such dramatic action proved to be the exception rather than the rule. (BNC ASB 1316-1317)

As another example of the role of scope in distinguishing between units, let us look at the relationship between propositions and the SoAs they contain. Consider example (75): ... I sat on one sofa and he on another. (BNC CDS 1128)

The fact that we have two conjoined SoAs here is indicated by the fact that each has its own locational modifier (it will be remembered that SoAs are characterised by being locatable in time and space). However, this conjunction of SoAs forms a single proposition, as can be shown by the fact that an adverb such as evidently, which indicates the speaker's attitude towards the content (in this case referring implicitly to a source of evidence) has scope over both SoAs: 
Hengeveld and Mackenzie (in preparation) also provide evidence for the units they propose from the selective marking of those units in some languages. For example, they show that in languages such as Turkish, the morphological marker of interrogative mood can be added to a structural unit of any syntactic type, so distinguishing the illocutionary Act itself from its syntactic manifestations. Similarly, they point out that in languages such as Samoan and Tagalog there is morphosyntactic marking of the distinction between referential and ascriptive Subacts.

Also relevant to the distinctions between units is evidence which was accumulated in favour of the layering scheme in earlier versions of FG. It will be remembered that in Dik's (1989, 1997a) presentation of FG, the underlying structure of the clause had four layers, corresponding to the predicate and terms (level 1), the predication (level 2), the proposition (level 3) and the speech act (level 4). Each of these levels is recognised in FDG, though as we have seen the arrangement is somewhat different: within the representational level, we have properties, individuals, locations and times (corresponding to level 1 of Dik's scheme) which are combined into SoAs (at level 2 for Dik), which are contained within propositional contents (analogous to level 3); the interpersonal level, which is 'higher' in the FDG model than the representational, accounts for the speech act properties of utterances (analogous to level 4). Evidence which demonstrated the layering of the four levels in FG is thus still relevant to FDG.

The evidence initially presented by Hengeveld for his layering scheme is concerned primarily with the validation of certain hypotheses which can be derived from the proposed ordering and classification of operators. Firstly, Hengeveld (1989: 141) hypothesises that the preferred order of operators, in terms of their realisation in clauses, will be ' $\pi_{4} \pi_{3} \pi_{2} \pi_{1}$ Predicate' or 'Predicate $\pi_{1} \pi_{2} \pi_{3} \pi_{4}$ ', where $\pi$ represents an operator and the subscripts indicate the level of the operator. Although it is not easy to find examples where all four categories are present, Hengeveld states that the ordering does indeed seem to apply to subsets of operators, and gives examples of Predicate $\pi_{1}$ $\pi_{2} \pi_{3}$ ordering from the Hidatsa (Siouan), Predicate $\pi_{2} \pi_{3}$ from Diegueño (Yuman) and Predicate $\pi_{2} \pi_{3} \pi_{4}$ from Quechua (Andean). Furthermore, West Greenlandic (Inuit) affords examples of $\pi_{3}$ ILL and ILL $\pi_{4}$, where ILL represents the marker of the illocutionary force itself. 
Secondly, it is proposed (Hengeveld 1989: 142) that the diachronic development of operators will follow the order from Level 1 to Level 4. This, Hengeveld notes, is compatible with the data presented by Bybee (1985) and Foley and Van Valin (1984).

Thirdly, it is expected that operators at a particular level will impose restrictions on the selection of operators at the next level below (Hengeveld 1989: 142). Again, this is borne out by the examples given by Hengeveld, which are concerned with interactions between illocutionary mitigation (Level 4) and commitment to the truth of the proposition (Level 3), desiderative mood (Level 3) and non-actuality of the SoA referred to by the predication (Level 2), and objective epistemic modality (Level 2) and phasal aspect (Level 1).

Fourthly, Hengeveld (1989: 144) concludes that operators can be most economically specified in the order $\pi_{4}>\pi_{3}>\pi_{2}>\pi_{1}$, since this makes it possible to narrow down progressively the options which are available in the construction of the underlying structure of the clause.

Dik (1989: 248) notes that the distinction between SoAs, as represented in predications, and potential facts, belonging to the proposition, had already been argued for by Vendler (1967/1957]). Dik (1989: 248-249) gives two linguistic arguments for it. Firstly, nominalisations which take the form of NPs (e.g. John's death) can occur in both predicational (SoA) and propositional (potential fact) contexts (John's death surprised me/occurred at noon), whereas those with the form of a non-finite clause (e.g. John's having died) are grammatical only in propositional contexts (John having died surprised me/*occurred at noon). Secondly, more verbal forms of nominalisation are appropriate for representing potential facts (as in John deplored Peter's driving the car recklessly, where it is the fact that Peter drove the car recklessly that is deplored), whereas more nominal types of nominalisation are suitable for SoAs (John deplored Peter's reckless driving of the car, where it is the reckless way in which Peter drove the car which John disapproves of). Hence, as Dik points out, a sentence such as John deplored Peter's driving is ambiguous between a reading in which John deplores the fact that Peter drove, and one in which it is the manner of driving which is deplored. 
Hengeveld (1989: 145) also hypothesises that subordinate constructions will be classifiable in terms of the highest layer which is represented in them. This entails that such a construction cannot contain a layer of a particular level without also containing all layers below that level, and that operators which are associated with the particular layers which are contained in a subordinate construction will be realisable within that construction. Hengeveld examines these claims in relation to the areas of complement constructions and adverbial satellites, these also being the areas which have been studied most in subsequent work. Dik and Hengeveld (1991) build on the account of complementation given in Hengeveld (1989), by examining in detail the complements taken by perception verbs.

In relation to adverbial satellites, Hengeveld (1989) concentrates on their function rather than their internal structure, showing that definitions can be provided for predicate, predication, proposition, illocution and clause satellites, and that these definitions are similar to those for the corresponding operators, the difference being that satellites constitute lexical means for the realisation of meaning, while the realisation of operators is grammatical. Hengeveld also discusses the structures of restrictive vs. non-restrictive types of satellite.

More detailed evidence for the layer-based classification of adverbial satellites is given in Dik et al. (1990). They first present a more delicate classification of such satellites in terms of the semantic domains covered by adverbials at each level in the hierarchy. They then present evidence for formal and behavioural differences, firstly between representational (predicate and predication) and interpersonal (propositional and illocutionary) satellites, and then between satellites within each of these levels. In the current context of FDG, in which the propositional layer is no longer seen as interpersonal, some of these arguments need to be re-examined. The foregoing summary is concerned only with the FUNCTION (or EXTERNAL STRUCTURE) of adverbial satellites within the sentence. Dik et al. also discuss the INTERNAL STRUCTURE of such satellites, that is their degree of complexity in terms of whether they themselves have a structure at the level of a predicate (e.g. repeatedly), a term (e.g. on the platform), a predication or SoA (e.g. after leaving the train) or a proposition (e.g. because he wanted to talk to him). They claim that all combinations of internal and external structure are possible, except that no satellites are found to 
have the external structure of a predicate and the internal structure of a proposition. A much more detailed semantically-based classification of the internal structure of adverbial clauses is presented in Hengeveld $(1996,1998)$

Hengeveld also provides evidence for the layering model from the behaviour of nonverbal (e.g. adjectival, nominal) predicates. He hypothesises that linguistic predicability follows a hierarchy such that "if a language can apply a predicate of a certain class to third order arguments, it can also apply a predicate of that class to second order and first order arguments" (Hengeveld 1990b: 116). He shows that adjectival predicates in English, Vietnamese (Austric) and Abkhaz (Caucasian) support this hypothesis, in that English can apply adjectival predicates to third, second and first order arguments, while Vietnamese can use adjectives only with first and second order arguments, and Abkhaz only with those of the first order.

Before leaving the area of evidence for layering at clause level, we should mention to the proposals of Anstey (2002), which suggest radical changes to Hengeveld's layering model. ${ }^{21}$ This work will not be discussed here, since it is updated and revised in the paper by Anstey in the present volume.

Finally, we turn to structure of the NP. Rijkhoff (2002: Chapter 10) ${ }^{22}$ assesses the evidence for the layered structure of the NP which can be adduced from scoping phenomena. He proposes a Principle of Scope $(\mathrm{PoS})$ which states that "[m]odifiers tend to occur next to the part of the expression that they have in their scope" (Rijkhoff 2002: 313). This principle implicitly predicts that constituents which form part of the same layer of underlying NP structure are expressed in a continuous sequence. It also predicts explicitly that both operators and satellites will come just before or just after whatever it is that they have within their scope. It interacts with the Principle of Head Proximity, according to which the heads of different domains (e.g. sentences, NPs) stay as close as possible. Also relevant to ordering within the NP is the Principle of Domain Integrity, which holds that the constituents of a single domain prefer not to be interrupted by other, embedded domains. Rijkhoff discusses the eight predicted

\footnotetext{
${ }^{21}$ These proposals are refined and extended in Anstey's contribution to the present volume.

${ }^{22}$ This chapter is an updated version of Chapter 10 of his 1992 book.
} 
ordering patterns for simple NPs with only a demonstrative, a non-lexical numeral and an adjective in addition to the head noun, all as free constituents of the NP. The orderings in the languages in his sample conform to these patterns. Although only six of the eight predicted orderings were found in Rijkhoff's sample, the other two have been attested in languages outside the sample (Rijkhoff, this volume).

Hengeveld (2004b, forthcoming) points out that his schema for the NP (see §5.1) allows us to account for the different values of poor in a poor driver, where the adjective modifies the property of being a driver (i.e. $\sigma^{f}$ ) in the most recent representation), a poor man, in which it selects a subclass of the entities referred to by the head noun man $\left(\sigma^{\mathrm{x}}\right)$, and poor guy!, where the adjective encodes a subjective attitude on the part of the speaker $\left(\Sigma^{\mathrm{R}}\right)$.

\subsection{The relationship between layering and the levels of syntax, semantics and pragmatics}

One of the main problems with Dikkian FG was that the roles of syntax, semantics and pragmatics were not clear. There was no well-defined syntactic level in FG: syntax came in only via the syntactic functions of subject and object and the expression rules which generated morphological patterns and word order relationships (as well as intonation) in response to the properties of the underlying clause structure.

Neither was there any level in the model which was essentially pragmatic in nature. One of Hengeveld's aims in developing FDG was to make a clear distinction between morphosyntax, semantics and pragmatics, and to put into practice Dik's (1997a: 8) dictum that "[s]emantics is regarded as instrumental with respect to pragmatics, and syntax as instrumental with respect to semantics". This is achieved by equating the interpersonal level with pragmatics, and the representational level with (decontextualised) semantics, and introducing a separate morphosyntactic level. The fact that the interpersonal level sits at the top of the model, and is invoked first in language production, shows the priority of pragmatics over semantics, and the position of the morphosyntactic level 'below' the representational and interpersonal levels reflects its role in serving the pragmatics and semantics (see Anstey 2004). 
With this clarification in the relationships between levels of the grammatical component and the traditional levels of syntax, semantics and pragmatics comes a reinterpretation of functions in FDG (Hengeveld 2004b: 373). In accordance with the suggestions made by Cornish (2004) and Mackenzie (2004), pragmatic functions such as Topic and Focus are now assigned, as we have seen, at the interpersonal level. Semantic functions are situated at the representational level as in earlier accounts of FG. The syntactic functions are now located at the new morphosyntactic level, and their assignment is seen as the result of the result of taking into account both pragmatic (interpersonal) and semantic (representational) factors. The perspectivising role of syntactic functions postulated in Dikkian FG is thus now seen as the result of basic underlying pragmatic and semantic considerations.

\subsection{Typology and language universals}

From its inception, FG has been strongly committed to the criterion of TYPOLOGICAL ADEQUACY, according to which the theory must aim to be equally applicable to all language types, and must take full account of both the similarities and differences between languages (Dik 1978: 8, 1989: 14, 1997a: 14-15). Indeed, Dik's view was that such a requirement is "implicit in the very notion of linguistic theory" and that it "obviously entails the necessity of using data from a wide variety of languages both in the setting up and in the testing of general linguistic hypotheses" (1978: 8).

This concern with typological adequacy is just as prominent in FDG as it was in earlier versions of FG. Hengeveld and Mackenzie (2006: 669) comment that "[1]inguistic typology, the study of the principles underlying formal variation across the languages of the world, is an essential source of inspiration for FDG, since the theory aims at developing a framework for the systematic description of all possible human languages". These authors go on to point out that the study of typology within FDG must go beyond the syntactic and morphological studies which are so common in the literature, to look at pragmatic and semantic aspects.

The literature offers abundant examples of the typological concerns of FDG. For instance, the argumentation in favour of the layered structures at the interpersonal and 
representational levels in Hengeveld and Mackenzie (in preparation) draws upon a very wide range of typologically diverse languages.

Typological work in previous versions of FG is, of course, also relevant to FDG. For instance, Hengeveld's original proposal for an underlying structure with four layers, and for the scoping of operators at those layers, is a hypothesis about all human languages, and in its formulation evidence is adduced from a number of typologicallyunrelated languages. Likewise, the detailed proposals for the classification of complement and satellite types according to the layering model are claimed to be of universal applicability. Differences between languages are explicitly recognised in the postulation of implicational hierarchies of the form 'If a language has/does $\mathrm{X}$ then it will have/do Y': for instance, we saw that for adverbial satellites Hengeveld (1996, 1998 ) proposes a hierarchy $2^{\text {nd }}$ order $>3^{\text {rd }}$ order $>4^{\text {th }}$ order, and then hypothesises that if some language uses a dependent verb form in an adverbial clause designating an entity at some point in the hierarchy, it will also use a dependent form for any entity which is higher up the hierarchy (i.e. of lower order), the reverse applying to independent realisations.

\section{Conclusion: Summary of similarities and differences across theories}

By way of conclusion, we offer Table 4, which summarises the main similarities and differences among the main theories we have discussed here, and their variants. 